\title{
XIIIème CONGRES DE LA SALF \\ NANCY, 12-14 décembre 1996
}

Résumés des communications affichées

\section{TESTICULE - SPERMATOGENESE}

87 Reconstruction tridimensionnelle du mésonéphros murin au cours de son développement. M-D. VASQUEZ, P. BOUCHET, B. FOLIGUET, H. GERARD, J-L. MALLET, B. LEHEUP.

L'aromatase chez le Pleurodèle (Amphibien Urodèle): activité et influence d'inhibiteurs dans la différenciation du sexe des gonades. D.CHARDARD, A. CHESNEL, C. DOURNON.

$88 \quad$ Effets des transforming growth factors $\beta 1$ et $\beta 2$ sur la gamètogenèse dans le testicule foetal de rat in vitro. R. OLASO, J. PREPIN, P.DURAND, R. HABERT.

89 ABP Sertolienne et synthèse de l'ADN dans les cellules germinales du rat et de la souris prépubères. A. GERARD, A. CLERC, M. ADAM, P. FRANCK, F. NABET, J. CLOSSET, G. HAMMOND, H. GERARD.

90 Effets du traitement Médroxyprogestérone-testostérone sur la spermatogenèse et l'ABP intratesticulaire chez le rat adulte. S. ES SLAMI, J-C. SOUFIR, P. FRANCK, P. NABET, H. GERARD, A. GERARD.

91 Identification d'un récepteur commun à la $\beta$-lactoglobuline et la rétinolbinding protein au niveau,des cellules germinales bovines mâles. A. MANSOURI, T. HAERTLE, A. GERARD, H. GERARD, J.L. GUEANT.

92 Relation entre spermatogenèse et concentration en oestrogène dans la veine testiculaire chez le bélier. BP. SETCHELL, C. PERREAU, C. KUNTZ, J. SAUMANDE, J. FONTAINE, A. LOCATELLI, MT. HOCHEREAU-DE-REVIERS.

93 Absence de régulation négative des ARN messagers du récepteur à la FSH dans les biopsies testiculaires de patients présentant un trouble de la spermatogenèse. $H$. LEJEUNE, C. BREBANT, P. COUSIN, N. BERGER-DUTRIEUX, M. DEVONEC, M. PUGEAT.

94 Protéines de liaison à l'actine dans le testicule humain. R. ROUSSEAUX-PREVOST, B. DELOBEL, J.M. RIGOT, E. HERMAND, P. DANJOU, E. MAZEMAN, J. ROUSSEAUX.

94 L'ascension inconstante du testicule est un facteur de risque potentiel pour la spermatogenèse des hommes inféconds. R. MIEUSSET, L.E. BUJAN, G. MASSAT, A. MANSAT, F. PONTONNIER.

\section{QUALITE DU SPERME ET DES SPERMATOZOIDES}

\section{Méthodes d'évaluation et marqueurs}

95 Evaluation de la qualité du sperme de patients fertiles en Slovénie pendant la période 1983-1995. B. ZORN, I. VIRANT-KLUN, C.VJETICANIN, H. MEDEN-VRTOVEC, T. TOMAZEVIC.

96 Mesure et rôle du PH intracellulaire dans la mobilité du sperme humain. S. HAMAMAH, E. MAGNOUX, D. ROYERE, C. BARHTELEMY, J-L. GAITI. 

CHOT, P. FOUCAULT, A-M. PALLUEL.

Anticorps anti-spermatozoïde et paramètres du mouvement dans les infertilités masculines. S. PILIKIAN, R. LEVY, M. BENCHAIB, G. PITAVAL, J.F. GUERIN.

Comparaison entre la cytométrie en flux du tissu testiculaire et les altérations de la spermatogenèse chez les patients hypofertiles à risque de carcinome in situ du testicule. $L$. SIBERT, N. RIVES, F. GOBET, E. BARRET, C. PFISTER, B. MACE.

Détection des disomies des chromosomes $4,5,6,9,13,14,20,21,22$ dans les spermatozoïdes humains à l'aide de sondes de peinture chromosomique. N. RIVES, S. MAZURIER, V. DUCHESNE, D. BELLET, G. JOLY, L. SIBERT, B. MACE.

\section{Qualité du sperme et stratégie d'AMP}

100 Place et valeur du test post-coïtal dans l'investigation du facteur masculin des couples admis en procréation médicalement assistée. Y. SOFFER, S. KAUFMAN, A. RAZIEL, S. FRIEDLER, A. HERMAN, I. BUKOVSKI, R. RON-EL.

1015 années d'inséminations intra-utérines avec sperme du conjoint (IIUAC): quelles conclusions en tirer? O. PAULMYER-LACROIX, L. MOLLE, A. NOIZET, A. GUERIN, M. MOLLAR, M. GAMERRE, J.M. GRILLO.

102 Apport stratégique du bilan complémentaire spermiologique après échec de fécondation in vitro. M. DANIEL, O. PAULMYER-LACROIX, M. MOLLAR, A. NOIZET, A. GUERIN, M. GAMERRE, J.M. GRILLO.

103 Influence de la morphologie des spermatozoïdes sur le fécondation, le clivage et la qualité embryonnaire. F. EUSTACHE, H. LUCAS, J. AUGER, C. POIROT, J.P. WOLF et P. JOUANNET.

104 Autoconservation du sperme chez les blessés médullaires: expérience du CECOS de Bordeaux. P. N'GUYEN VAN TAM, C. MATHIEU, H. MEKLA, J. MORAND, T. BLANDIN, G. MAYER.

\section{Infection du sperme et AMP}

105 Le testicule organe cible du cytomégalovirus murin: impact sur la descendance. I. CERUTTI, G. BLANC-LAYRAC, A.M. COURTOT, J. TESTART.

106 Cytomégalovirus et procréation médicalement assistée. R. LEVY, B. KEPPI, F. NAJIOULLAH, S. BOSSHARD, D. THOUVENOT, B. LINA, M. AYMARD, J. LORNAGE, J.F. GUERIN.

106 Prévalence de l'infection à Chlamydia Trachomatis étudiée par 3 techniques diagnostiques dans le tractus génital de 100 hommes de couple infertile. A. KERJEAN, J. AUGER G. PAUL, P. NEVOT, P. JOUANNET, M.V. ASSOUS.

\section{Cryoconservation}

107 Rôle du liquide séminal dans la cryopréservation des spermatozoïdes humains. V. CHEVALIER, C. NOUAILLES, B. SION, D. BOUCHER, G. GRIZARD.

108 Espèces et sous-espèces phospholipidiques du spermatozoïde humain : Relation avec la mobilité et la résistance à la congélation. S. ZEKRI, P. THEROND, J. AUGER, P. JOUANNET

\section{AZOOSPERMIE ET ICSI}

\section{Bilan de l'azoospermie et de la qualité des gamètes avant ICSI}

109 Intérêt des marqueurs biochimiques séminaux pour la classification des azoospermies : apport de l'analyse par courbe roc. A. KERJEAN, J.AUGER, B. CHERRUAU, G. SARFATI, D. NGUYEN-DAI, P. JOUANNET. 
111 Détection de microdélétions du chromosome $\mathrm{Y}$ chez des patients azoospermiques. $R$. ROUSSEAUX-PREVOST, J.M. RIGOT, F. COLLIER, E. HERMAND, B. DELOBEL, P. LESUR, M.F. CROQUETTE, A. GAUTHIER, J. ROUSSEAUX.

112 Recherche de micro-délétions du chromosome $\mathrm{Y}$ chez des patients azoospermes. L. BUJAN, H.L. PLAISANCIE, G. BOURROUILLOU, A. MANSAT, F. PONTONNIER, R. MIEUSSET.

113 Recherche de délétions moléculaires au niveau du gène daz chez 22 patients infertiles. $F$. FELLMANN, C. ROUX, M-C. CLAVEQUIN, J.L. BRESSON.

113 L'utilisation de spermatides en fécondation in vitro: fiction ou réalité ? I. VIRANT-KLUN, B. ZORN, A. MAN, H. MEDEN-VRTOVEC, T. TOMAZEVIC.

\section{Méthodes d'obtention de gamètes en vue d'ICSI}

114 La recherche in extremis de spermatozoïdes dans l'éjaculat permet-elle d'éviter, dans les azoospermies non-obstructives, un prélèvement testiculaire de sperme pour la fertilisation assistée ? Y. SOFFER, D. STRASSBURGER, S. KAUFMAN, A. RAZIEL, S. FRIEDLER, D. KOMAROVSKI, O. BERN, I. BUKOVSKI, R. RON-EL.

115 La cryo-préservation des spermatozoïdes prélevés sur les testicules dans les azoospermies non-obstructives. Y. SOFFER, S. FRIEDLER, A. RAZIEL, D. STRASSBURGER, S. KAUFMAN, D. KOMAROVSKI, O. BERN, I. BUKOVSKI, R. RON-EL.

116 Le prélèvement testiculaire à l'aiguille ; technique d'avenir. C. WITTEMER, J. OHL, $K$. BETTAHAR-LEBUGLE, C. FATH, L. MOREAU, D. JACQMIN, P. DELLENBACH.

\section{ICSI et azoospermie : résultats}

117 ICSI et Azoospermie. M. BAILLY, F. MERLET, J-P. BISSON.

118 Micro injection avec spermatozoïdes testiculaires : Comparaison avec les résultats globaux de l'ICSI au centre AMP de la maternité Hôpital Sainte Croix de Metz. J.P. RAGAGE, T. CASSIER, J.M. BOUSCHBACHER, T. SCHWEITZER, F LESTRADE.

119 Grossesse obtenue après injection intraovocytaire de spermatozoïdes testiculaires cryoconservés et immobiles après décongélation. N. RIVES, L. SIBERT, B. CLAVIER, V. DELABROYE, S. MAZURIER, B. MACE.

Intérêts de l'ICSI avec recueil chirurgical de spermatozoïdes dans les azoospermies obstructives, secrétoires et les anéjaculations. JPh, WOLF, N. THIOUNN, V. IZARD, C. POIROT, A. BOUKER, C. LEBON, B.DEBRE, A. JARDIN, JR. ZORN, S. EPELBOIN,P. JOUANNET.

\section{ACTUALITES EN UROLOGIE ANDROLOGIE}

\section{Contrôles de la fonction érectile}

121 Approche morphologique de la modulation ocytocinergique de l'érection chez le rat. $F$. VERONNEAU-LONGUEVILLE, Y. TANG, O. RAMPIN G. BENOIT A JARDIN, M-J. FREUND-MERCIER, A. CALAS, F. GIULIANO.

122 Vascularisation artérielle du pénis : nouvelles données anatomiques et implications cliniques. S. DROUPY, G. BENOIT, F. GIULIANO, A. JARDIN.

123 Notre expérience des auto-injections intracaverneuses dans les dysfonctions érectiles (de): Moxisylyte, Prostaglandine El (PGEI) et association papaverine-phentolamine-PGEI. A. LEMAIRE, J. BUVAT. 
124 Le Sildenafil (VIAGRA,), un nouveau traitement oral des dysfonctions érectiles : Etude multicentrique en double insu contre placebo chez 351 patients. J. BUVAT, C. GINGELL, A. OLSSON, A. JARDIN, A. LEMAIRE, F. GIULIANO, I. OSTERLOH, J. KIRKPATRICK, M. CUDDIGAN et le Groupe Multicentrique.

125 Alprostadil-Alphadex versus moxisylyte dans le traitement des dysfonctions érectiles par injections intracaverneuses: Résultats d'une étude multicentrique en double insu. $J$. BUVAT, D. MORLIER, P. COSTA, D. CHEVALLIER, M. ZERLIB, A. LEMAIRE, et le Groupe d'étude.

\section{Imagerie médicale}

126 Echo-Doppler des veines spermatiques avant et après embolisation: une meilleure classification des varicoceles intra-cliniques? F. CORNUD, D. DELAFONTAINE, E. AMAR, F. OLIVENNES, R. FRANCHIN

126 Echographie et IRM endorectales de l'obstruction des canaux éjaculateurs chez l'homme hypofertile. F. CORNUD, E. AMAR, D. DELAFONTAINE, X. BELIN, J. MANDELBAUM, O. HELENON, J.F. MOREAU.

\section{Hormones, anti-hormones, sexualité}

127 Effets métaboliques d'un traitement par oestrogènes naturels et antiandrogènes chez les hommes transsexuels. Kh. ARAFAT, M. HANSS, P. MOULIN, G. TRONCY, M. DECHAVANNE, F. BERTHEZENE, J. ROLLET.

127 Etude de la fonction sexuelle des hommes transplantés rénaux. B. BARROU, F. KIRSCHNOIR, J. HUBERT, G. FOURNIER, J. PETIT, T. LEBRET, B. CUZIN, G. KARAM, F. GIULIANO et les membres des Comités de Transplantation et d'Andrologie de l'Association Française d'Urologie.

128 Tamoxifene par voie orale : une alternative thérapeutique non chirurgicale dans le traitement de la maladie de la Peyronie ? L. SIBERT, E. BARRET, C. PFISTER, M. PLANET, P. GRISE. 


\section{TESTICULE SPERMATOGENESE}

\section{RECONSTRUCTION TRIDIMENSIONNEL- LE DU MESONEPHROS MURIN AU COURS DE SON DEVELOPPEMENT}

\author{
M.D. VAZQUEZ* ${ }^{*}$ P. BoucheT** , B. FoligueT*, \\ H. GeRARD*, J.L. MALLET ${ }^{\circ}$ ET B. LeheU* \\ *Département de Cytologie. Histologie et \\ Embryologie, Faculté de Médecine, \\ 9 avenue de la Forêt de Haye, BPI 84, \\ 54505 Vandoeuvre-les-Nancy, France; \\ ${ }^{*}$ Centre de Recherche Informatique de Nancy, \\ Bât LORIA, BP 239, \\ 54506 Vandoeuvre-les-Nancy, France. \\ ${ }^{\circ}$ Ecole Nationale Supérieure de Géologie de \\ Nancy, rue du Doyen Marcel Roubault, BP4O, \\ 54501 Vandoeuvre-les-Nancy, France.
}

\section{Introduction}

L'évolution structurale du mésonéphros segmenté murin a été analysée par visualisation sur modèles $3 \mathrm{D}$ reconstruits. Cette reconstruction tridimensionnelle s'établit à partir de coupes sériées histologiques d'embryons prélevés à 10.5 , $11.5,12.5,13.5,14.5$ et 15.5 jours embryonnaires.

\section{But}

Cette étude examine l'organisation spatiale des tubules mésonéphrotiques et précise toutes les connexions entre ces éléments et les canaux. Une comparaison mâle-femelle des changements morphologiques du mésonéphros est suivie en considérant trois embryons de chaque sexe pour chaque stade embryonnaire.

\section{Matériel et Méthodes}

Au moyen d'une chambre claire associée à un microscope optique, les contours des tubes mésonéphrotiques sont manuellement tracés puis scannés. Ils sont ensuite transformés en lignes polygonales fermées pour permettre la création de surfaces grâce à un procédé de triangulation. Après cette étape, un algorithme de lissage est utilisé afin de supprimer d'éventuels décalages dans les surfaces tubulaires réalisées, lequel s'effectue par une redistribution spatiale des sommets des triangles.

\section{Résultats}

A 10.5 jour embryonnaire, des tubules émergent du corps de Wolff, puis entre 11.5 et 13.5 jour embryonnaire, de tortueux tubules mésonéphrotiques liés au canal de Wolff et enroulés en forme de boucles, se développent pour finalement se dérouler alors que d'autres tubules non liés au canal de Wolff apparaissent. A 13.5 jour embryonnaire, le canal de Müller est distinct du canal de Wolff et s'épaissit chez les embryons femelles alors que démarre un processus de régression chez les embryons mâles. Inversement, le canal de Wolff s'épaissit pour participer au conduit génital mâle tandis qu'il s'affine et se réduit jusqu'à dégénérer dans le mésonéphros femelle. Ce processus de dégénérescence débute dans la portion craniale du mésonéphros et évolue dans le sens cranio-caudal.

\section{Discussion}

Grâce à cette modélisation, nous avons dénombré 4 à 6 tubules mésonéphrotiques, dirigés vers la gonade, éléments constitutifs du futur rete testis dans le testicule et résiduels dans l'ovaire. Les objets modélisés rendent compte d'une prédominance du canal de Wolff dans le mésonéphros mâle contre un rôle potentiel du canal de Müller dans le mésonéphros femelle. L'avantage de ce projet est d'améliorer notre compréhension des changements morphologiques et d'offrir, avec une haute définition, une approche tridimensionnelle de la différenciation mésonéphrotique normale.

\section{L'AROMATASE CHEZ LE PLEURODELE (AMPHIBIEN URODELE) : ACTIVITE ET INFLUENCE D'INHIBITEURS DANS LA DIFFERENCIATION DU SEXE DES GONADES}

\author{
D. Chardard, A. Chesnel, C. Dournon
}

Equipe "Génétique et Interactions cellulaires en Reproduction" Université Henri Poincaré, Nancy-1

L'Amphibien Urodèle Pleurodeles waltl présente un déterminisme génétique rigoureux du sexe de type ZZ/ZW lorsque les larves (têtards) sont élevées à la température ambiante $\left(18-22^{\circ} \mathrm{C}\right)$. Mais la différenciation sexuelle est sensible aux températures élevées et aux hormones sexuelles. Les 
individus de génotype sexuel femelle $\mathrm{ZW}$ placés à une température d'élevage de $32^{\circ} \mathrm{C}$ pendant une période précise de leur vie larvaire (période thermosensible) se différencient en mâles fonctionnels. Les individus de génotype sexuel mâle ZZ traités durant une partie de leur vie larvaire (période hormonosensible) au benzoate d'œstradiol se différencient en femelles fonctionnelles.

Des dosages d'activité aromatase réalisés sur des larves pendant et après la période thermosensible montrent une très forte activité chez les femelles ZW élevées à la température ambiante et une activité faible et stable chez les mâles $\mathrm{ZZ}$. Chez les femelles ZW, l'augmentation de l'activité précède de plusieurs jours la différenciation histologique du sexe des gonades.

Lors de l'inversion des individus ZW par la température d'élevage, l'activité aromatase est fortement diminuée et se retrouve au même niveau que celle des mâles $\mathrm{ZZ}$ élevés à $32^{\circ} \mathrm{C}$ ou à la température ambiante, témoignant de l'inversion sexuelle endocrinienne de ces animaux. Des chocs thermiques de 48 heures appliqués sur des larves femelles $\mathrm{ZW}$ ont montré que la température n'avait un effet inhibiteur sur l'activité aromatase que pendant la période thermosensible.

Un inhibiteur d'aromatase, le fadrozole, appliqué durant la période hormonosensible provoque une diminution de l'activité aromatase et l'inversion du sexe des gonades d'une partie des larves ZW traitées. Chez les individus ZW inversés en mâles, l'activité de l'aromatase dans les gonades est semblable à celle des gonades des larves $\mathrm{ZZ}$ élevées à la température ambiante.

Chez le Pleurodèle, l'un des points de contrôle de la différenciation et l'inversion du sexe des gonades pourrait être l'aromatase.

$-1$

\section{EFFETS DES TRANSFORMING GROWTH FACTORS $\beta 1$ ET $\beta 2$ SUR LA GAMETOGE- NESE DANS LE TESTICULE FOETAL DE RAT IN VITRO}

\author{
R. Olaso*, J. Prepin**, P. DuRAND ${ }^{\circ}$, R. Habert* \\ *INSERM-INRA U418, Université Paris 7, \\ 75251 Paris cedex 05 \\ **JE 349, Université Paris 575005 Paris \\ 'INSERM-INRA U418, Hôpital Debrousse, \\ 69322 Lyon.
}

Il a été récemment suggéré que le Transforming Growth Factor $\beta$, dont trois isoformes sont exprimées chez les Mammifères (TGF $\beta 1$, TGF $\beta 2$, TGF $\beta 3$ ) est un facteur susceptible de bloquer le cycle cellulaire et/ou d'induire l'apoptose dans de nombreux types cellulaires [1]. Or, nous avons montré précédemment par immunocytochimie que les TGF $\beta 2$ et $\beta 1$ sont présents dans le testicule foetal de Rat à partir de 13,5 et 14,5 jours post conception (jpc) respectivement [2 et 3]. En outre, en utilisant une technique de dosage biologique, nous avons détecté l'isoforme $\beta 1$ dans le milieu de culture de testicules foetaux [4]. Le but de notre travail a été de rechercher une intervention des TGF $\beta$ s dans la régulation du nombre de gonocytes pendant la vie fœtale.

\section{Matériel and Méthodes}

Les fœtus et leurs annexes embryonnaires sont prélevés à 13,5 jpc. Leur sexe est identifié par la révélation de la chromatine sexuelle de la membrane amniotique. L'ensemble testicule-mésonéphros est prélevé et cultivé en présence ou en absence de TGFJ3s. Le nombre total de gonocytes présents dans le testicule est déterminé par numération sur coupe histologique. L'activité mitotique des gonocytes est évaluée par détection immunocytochimique de l'incorporation de BrdU. L'apoptose des gonocytes est quantifiée par la révélation immunocytochimique de la fragmentation de l'ADN (méthode TUNEL).

\section{Résultats}

Les TGF $\beta 1$ et 2 sont capables de diminuer le nombre de gonocytes présents dans le testicule foetal. Cet effet est dose dépendant (Figure 1).

L'effet des TGFßs ne résulte pas d'une diminution de l'index mitotique des gonocytes (Figure 2A) mais d'une augmentation de l'apoptose (Figure 2B).

\section{Conclusions}

Ces résultats montrent que les TGF $\beta 1$ et $\beta 2$ sont des facteurs de régulation para et/ou autocrine potentiels de la spermatogenèse pendant la vie fotale ; mais la réalité physiologique de cette action reste à démontrer. 


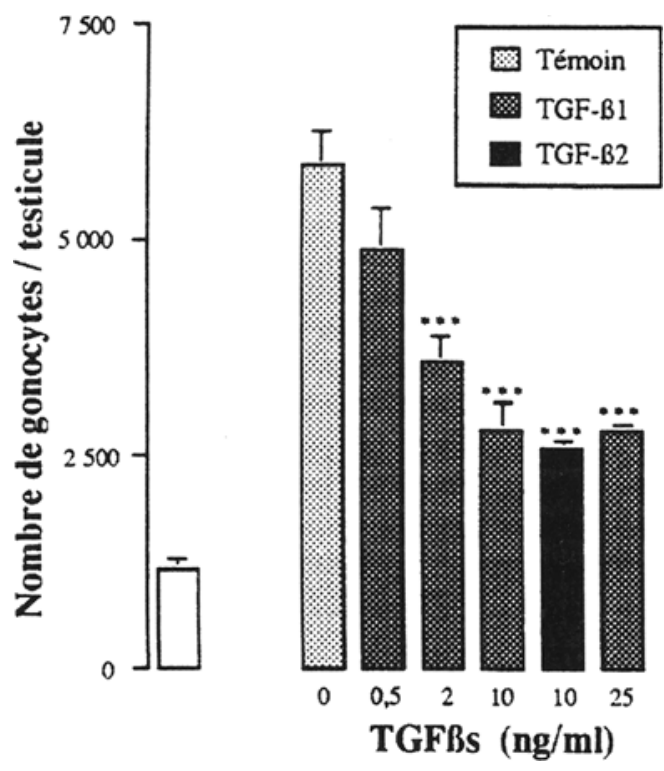

Figure 1: Effet des TGF $\beta$ s sur le nombre de gonocytes du testicule foetal de Rat in vitro.

Les gonocytes sont dénombrés avant (colonne blanche) et après (colonnes grisées) 2 jours de culture en l'absence (témoin) ou en présence de TGF $\beta 1$ ou $\beta 2$ à différentes concentrations. ${ }^{* * *} p<$ 0,001 en comparaison avec les valeurs témoins dans le test " $t$ " de Student.
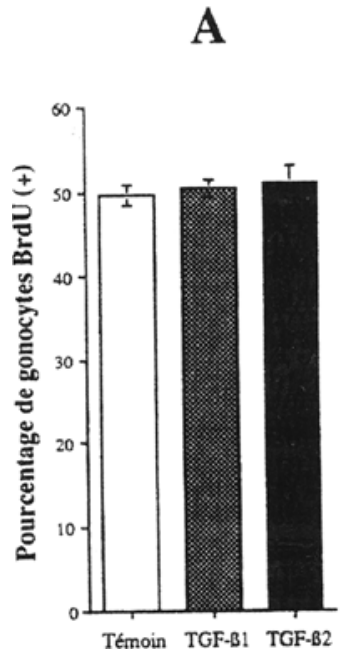

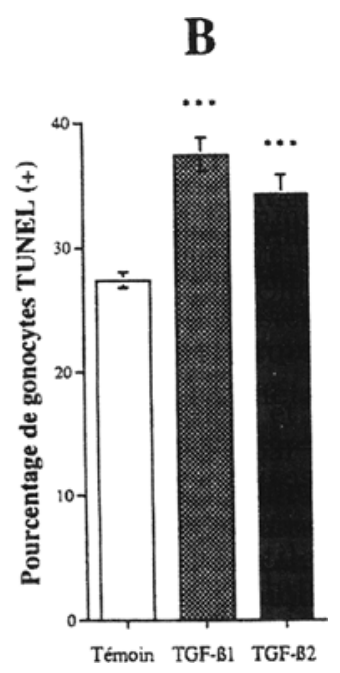

Figure 2: Effet des TGF $\beta$ s sur l'activité mitotique (A) et apoptotique (B) des gonocytes du testicule foetal de Rat in vitro.

Après 2 jours de culture en absence (témoin) ou en présence de $10 \mathrm{ng} / \mathrm{ml}$ de TGF $\beta 1$ ou de TGF 32 le pourcentage de gonocytes montrant une immunonéactivité positive pour le BrdU (A) ou pour la fragmentation de l'ADN (B) est évalué. ${ }^{* * *} p<0,001$ en comparaison avec les valeurs témoins dans le test " $t$ " de Student.

\section{REFERENCES}

1. Massague, J., Attisano, L. AND Wrana, J.L. (1994) : Trends Cell Biol. 4, 172-178.

2. Gautier C., Levacher C., Avallet 0., Vigier M., RoulllerFabre V., Lecerf L., SAEZ J. AND HaberT R. (1994) : Mol. Cell. Endocrinol. 99, 55-61.

3. Olaso R., Gautier C., Levacher C., Durand P., SAEZ J. AND HABERT R, : soumis.

4. Levacher C. Gautier C., Saez J. and Habert R. (1996) : Gth European Workshop on Mol. cell. Endocrinol. Testis. Geilo Norvvay. F 13.

\section{ABP SERTOLIENNE ET SYNTHESE DE L'ADN DANS LES CELLULES GERMINALES DU RAT ET DE LA SOURIS PREPUBERES}

A. GERARD*, A. ClerC*, M. AdAM*, P. FranCK**, F. NABET**, J. ClOSSET ${ }^{\circ}$, G. HAMMOND ${ }^{\circ}$, H. GERARD*

* Laboratoire d'Histologie-Embryologie, Faculté de Médecine de Nancy

** Laboratoire de Biochimie médicale 2, Faculté de Médecine de Nancy

- Laboratoire d'Endocrinologie Humaine de Liège, Belgique

${ }^{\circ}$ London Cancer research, Ontario, Canada.

\section{Introduction}

Nous avons montré chez le rat adulte que, in vitro, les spermatocytes meiotiques préleptotènes ont une intense activité d'internalisation de l'ABP sertolienne jusqu'au compartiment nucléaire (Gerard et col.,1994, 1995), De plus, l'ABP sertolienne additionnée au milieu de culture stimule l'incorporation de thymidine tritiée dans les cellules germinales (Gerard et col. 1996) suggérant fortement un effet sur les cellules germinales synthétisant de l'ADN, c'est à dire soit les spermatogonies prémitotiques (pic au stade IV), soit les spermatocytes méiotiques préleptotènes du stade VIII (Parvinen, 1993).

Pendant le développement postnatal, l'ABP est produite chez le rat à partir du $13 \mathrm{e}$ jour et présente un pic de sécrétion au $18 \mathrm{e}$ jour (Tindall et coll., 1975 ; Carreau et coll ; 1986) confirmé par la quantification des molécules d'ARNm d'ABP (Linder et coll., 1991). A cette période, la prolifération des cellules germinales s'accentue considérablement tandis que celle des cellules de Sertoli se ralentit. Notre but est donc d'étudier la 
présence d'ABP dans les cellules germinales et la réponse des cellules germinales à l'ABP pendant ces deux périodes clés.

\section{Méthodes}

La présence de l'ABP dans les cellules germinales de rat et de souris pendant le développement postnatal prépubère a été recherchée par immunocytochimie avec des anti- $\mathrm{ABP}$ de rat et anti $\mathrm{ABP}$ de souris. Puis nous avons testé in vitro, les effets de l'adjonction d'ABP/ SHBG recombinante sur la synthèse d'ADN dans des cultures de cellules germinales isolées de rat de 14, $18 \mathrm{JPN}$ et cultivées en présence de thymidine tritiée selon les méthodes décrites précédemment (Gerard,1995-1996) et les populations ont été contrôlées en cytométrie de flux.

\section{Résultats}

L'ABP est visible dans les spermatocytes dés leur 11e JPN chez la souris et le 13e JPN chez le rat. La protéine immunopositive est visible niveau membranaire et/ou cytoplasmique et nucléaire. Les spermatocytes qui s'engagent dans la méiose caractérisés par l'apparition des complexes synaptonémaux décelables en Microscopie électronique renferment de l'ABP au niveau cytoplasmique et nucléaire. Au $20 \mathrm{e}$ JPN, de nombreux spermatogonies et spermatocytes méiotiques sont immunomarqués. Ces types cellulaires seront encore immunomarqués chez la rat et la souris adulte. Les cellules germinales isolées à partir de rats de 14 JPN et 18 JPN et cultivées en présence d'ABP/SHBG recombinante montrent une viabilité améliorée et une stimulation de la synthèse de l'ADN mise en évidence par une augmentation significative de l'incorporation de thymidine tritiée. L'analyse du contenu en $\mathrm{ADN}$ révèle une augmentation significative du pic $4 \mathrm{C}$ en présence d'ABP pendant 24 et $48 \mathrm{~h}$ de culture.

\section{Discussion}

L'ABP est présente au niveau des cellules germinales dés la période prépubère et dés le départ de la méiose. A ce stade, l'ABP provoque un effet stimulant sur la synthèse de l'ADN.Ceci concorde avec nos résultats précédents de protocoles d'endocytose qui avaient montré des sites de fixation membranaires et une endocytose spécifique au niveau des spermatocytes préméiotiques et méiotiques jusqu'au niveau nucléaire. La récente découverte d'un signal d'adressage nucleaire sur certaines formes de transcrits de l'ABP (Joseph et coll ; 1996) permettrait d'expliquer la possibilité du transfert de l'ABP du compartiment cytoplasmique au compartiment nucléaire.

\section{En conclusion}

L'ABP pourrait intervenir comme facteur paracrine direct sur le contrôle des gènes de la prolifération des cellules germinales ou comme facteur intermédiaire de transcription de cette étape.

\section{EFFETS DU TRAITEMENT MEDROXY- PROGESTERONE-TESTOSTERONE SUR LA SPERMATOGENESE ET L'ABP INTRA- TESTICULAIRE CHEZ LE RAT ADULTE}

\author{
S. Es-SLAMI*, J-C. SOUfIR* P. FranCK** ${ }^{*}$, P. \\ NABET $^{* *}$, H. GERARD ${ }^{\circ}$, A. GERARD ${ }^{\circ}$ \\ * Groupe de Recherche en Urologie, Faculté de \\ Médecine-Kremlin-Bicêtre \\ ** Laboratoire de Biochimie Médicale 2, \\ ' Laboratoire d'Histologie Embryologie, Faculté \\ de Médecine de Nancy
}

\section{Introduction et but}

Des résultats précédents nous avaient montré que le traitement MPA (médroxypogestérone $8 \mathrm{mg} / \mathrm{kg} / \mathrm{j}$ )-'T (testostérone $\mathrm{lmg} / \mathrm{kg} / \mathrm{j}$ ) chez le rat adulte provoquait une baisse de la testostérone intratesticulaire et une diminution de la population de cellules germinales méiotiques et postméiotiques (Es-slami et al. 1996). Ce traitement entraîne une baisse de la FSH et de la LH plasmatiques de $50 \%$ et $95 \%$ respectivement (Lobl et al. 1983).

Nous avons voulu, par une approche quantitative plus large, analyser les cellules de l'épithélium séminifère en cytométrie de flux, et par une étude histophysiologique examiner la différenciation des spermatides et la présence de l'ABP dans l'épithélium séminifère dont la production est FSH et testostérone dépendante (Danzo et al. 1990).

\section{Matériel et méthodes}

Des rats Sprague Dawley adultes sont traités par MPA-T pendant 55 jours. Les tubes séminifêres d'un testicule sont dilacérés après élimina- 
tion de l'albuginée et une digestion enzymomécanique est réalisée pour isoler les cellules (Gérard et al. 1994) et les analyser en cytométrie de flux (Bedjou et al. 1995). Le second testicule est fixé pour étude histologique. Les sites de fixation de la lectine PNA (marqueur de l'acrosome) ont été révélés par incubation avec le complexe PNA-FITC. La présence de l'ABP a été recherchée à l'aide d'un anticorps anti-ABP testiculaire de rat. Nous avons réalisé des contrôles de spécificité pour ces deux marqueurs.

\section{Résultats}

1. Chez les rats traités, la cytométrie de flux a révélé une augmentation relative des cellules en phase $\mathrm{S}$, diploïdes et tétraploïdes par rapport aux cellules haploïdes.

2. Les sites PNA positifs chez les traités sont similaires à ceux des témoins et concernent toutes les spermatides depuis le stade du granule acrosomique jusqu'aux spermatides allongées. Cette réaction a montré en plus des modifications du nombre et de la distribution des spermatides dans la paroi séminifère des rats traités.

3. L'ABP immunopositive est présente dans les cytoplasmes sertoliens ainsi que dans certaines cellules germinales. En plus nous avons noté, chez les rats traités, la présence d'un nombre plus élevé de spermatocytes marqués parmi lesquels des spermatocytes métaphasiques (en stade XIV).

\section{Discussion et Conclusions}

1. Les résultats de cytométrie de flux confirment et complètent nos précédents résultats d'histologie quantitative.

2. Il n'y a pas d'arrêt de la spermiogenèse et la formation de l'acrosome n'est pas altérée par le traitement; mais on note toutefois une modification du nombre des spermatides PNA positives et de leur position dans la paroi des tubes séminifêres des rats traités.

3. Les cellules de Sertoli des rats traités continuent de synthétiser l'ABP malgré la baisse de la testostérone intratesticulaire et de la FSH plasmatique. Nos résultats sont en accord avec ceux de Pogach et al. (1993) qui montrent que sous l'effet d'un traitement par antagonistes de GnRH, l'ABP intratesticulaire, non seulement ne diminue pas mais augmente alors que le taux de l'ABP épididymaire est effondré.
4. Le marquage des spermatocytes chez les traités suggère une modification du métabolisme de ces cellules sous l'effet de la déprivation androgénique du testicule causée par le traitement (modification des récepteurs d'ABP et/ou du taux d'internalisation de l'ABP ?...).

$\bullet \bullet$

\section{IDENTIFICATION D'UN RECEPTEUR COMMUN A LA B-LACTOGLOBULINE ET LA RETINOL-BINDING PROTEIN AU NIVEAU DES CELLULES GERMINALES BOVINES MALES}

\author{
A. Mansouri*, T. Haertle** ${ }^{*}$, A. Gerard ${ }^{\circ}, \mathrm{H}$. \\ GERARD $^{\circ}$, J.L. GuEANT* \\ * Laboratoire de Biochimie Cellulaire et Molécu- \\ laire en Nutrition, Faculté de Médecine, 54500 \\ Vandoeuve, \\ ** LEIMA-lNRA 44026 Nantes Cedex, \\ - Laboratoire d'Histologie-Embryologie, Faculté \\ de Médecine, 54500Vandoeuvre
}

La vitamine $A$ (rétinol) est un micro-nutriment essentiel pour le maintien d'une activité physiologique normale du testicule et de l'épididyme. La $\beta$-lactoglobuline (BLG) est une protéine qui présente une grande similarité de structure avec la "retinolbinding protein" (RBP) qui transporte le rétinol au niveau de la circulation. La BLG peut lier une ou deux molécules de rétinol.

Nous avons recherché l'existence de sites de liaison spécifiques de la BLG et de la RBP au niveau de préparations membranaires de cellules germinales bovines mâles.

La liaison aux préparations membranaires de la BLG variant A marquée à l'iode 125 ([125I]BLGA) est réversible, $\mathrm{pH}$-dépendante avec un maximum à $\mathrm{pH} 5$. La liaison est réversible avec des constantes cinétiques $\mathrm{K}_{1}$ et $\mathrm{K}_{-1}$, égales respectivement à $2.26 \pm 0.8 \times 10^{5} \mathrm{M}^{-1} \mathrm{~min}^{-1}(\mathrm{n}=3)$ et $0.016 \pm 0.004 \mathrm{~min}^{-1}(\mathrm{n}=3)$. L'analyse de Scatchard a montré qu'il existe une seule classe de sites de liaison avec $12.38 \pm 4.62 \times 10^{12}$ sites par $\mathrm{mg}$ de protéines membranaires et une constante de dissociation $(\mathrm{Kd})$ estimée à $26.43 \pm 2.68 \mathrm{nM}$ $(n=3)$. L'inhibition de la liaison de la [125I]-BLGA a été obtenue en présence de protéines non marquées tels que la BLG variant $A$, la BLG variant $B$, la $B L G$ variant $A$ complexée au rétinol et la RBP ; aucune inhibition n'a été observée en pré- 
sence d'albumine sérique bovine (BSA) ou de lactoferrine.

La [125I]-BLGA a été également incubée avec une fraction membranaire solubilisée dans le triton X-100. Le passage du mélange en gel filtration Superose 12B a permis de mettre en évidence un complexe protéine-récepteur de haut poids moléculaire. Ce complexe diminue fortement ou disparaît en présence de BLGA non marquée ou d'EDTA.

En conclusion, cette étude a permis d'identifier des sites de liaison communs à la RBP et à la BLG libre ou complexée au rétinol au niveau des cellules germinales bovines mâles. Ces résultats évoquent l'existence d'un récepteur dont le rôle dans l'internalisation de la vitamine A dans les cellules germinales reste à déterminer.

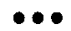

\section{RELATION ENTRE SPERMATOGENESE ET CONCENTRATION EN OESTROGENE DANS LA VEINE TESTICULAIRE CHEZ LE BELIER}

BP Setchell *,C Perreau **, C Kuntz**, J SaUMANDE**, J FONTAINE **, A LOCATELLI*, MT HOCHEREAU-DE REVIERS**

* Dpt Animal Sciences, Waite Agr. Res. Inst. Uuuv. Adelaide, Glen Osmond, SA 5064, Australia.

** PRMD, URA 1291, Centre INRA de Tours, 37380 Nouzilly, France.

\section{Question}

Y -a-t-il une relation ente la sécrétion d'oestogène par le parenchyme testiculaire dans la veine testiculaire et l'état de la spermatogenèse?

\section{Approche}

Comparaison des concentrations d'œstrogène et de testostérone chez des béliers normaux ou après une élévation de température scrotale; béliers normalux ou hypophysectomisés supplémentés par de l'extrait hypophysaire ovin (hypo/ext.h), pour éliminer les variations de rétrocontrôle de l'axe hypopthalamo-hypophysaire (Setchell et al 1991).

\section{Matériel et méthodes}

17 béliers Ile de France en saison sexuelle dont 11 hypohysectomisés. Chauffage testiculaire sous anesthésie par immersion du scrotum pendant 45-60 min dans un bain à $45^{\circ} \mathrm{C}(6$ hypo/ext.h +3 normaux). 20 jours plus tard, anesthésie de tous les béliers; cannulations des veines testiculaire et jugulaire ( 3 prélèvements par testicule espacés de $15 \mathrm{~min}$ ). Dosages FSH, LH, testostérone et œstrogène par RIA (Setchell et al 1991). Castration, pesée, fixation et histologie (Hochereau-de Reviers et al 1993).

\section{Résultats}

1) Le traitement par l'extrait hypophysaire a été surdosé. Il a augmenté les concentrations moyennes du plasma périphérique en FSH (x 8), en LH (x5), en testostérone et en œstrogène (x 5) par rapport aux témoins normaux. Dans le plasma veineux testiculaire, les concentrations en testostérone et en cstrogène sont augmentées respectivement par $\times 50$ et $\times 14$. Le poids testiculaire a été augmenté par x 1,3; accroissement $\mathrm{x} 1,6$ de la production quotidienne de spermatocytes I leptotène et $x 1,13$ des spermatides rondes, sans modifications du nombre des cellules de Sertoli. L'augmentation de FSH entraîne celle de la sécrétion d'œstrogène dans le plasma veineux testiculaire $(r=0,69)$.

2) La destruction de la spermatogenèse par le chauffage entraîne une régression du poids testiculaire de 40 à $50 \%$. Celle-ci correspond à une atteinte de la spermatogenèse, dès les spermatogonies $\mathrm{A} 1$, et à une diminution des productions de spermatocytes I et des spermatides rondes de 60 et $90 \%$ respectivement (béliers normaux ou hypo/ext.h).

3) La destruction de la spermatogenèse n'entrâेne pas de modification de la concentration d'oestrogène dans le plasma veineux testiculaire. La

Oestrogène et testostérone dans la veine testiculaire et spermatogenèse

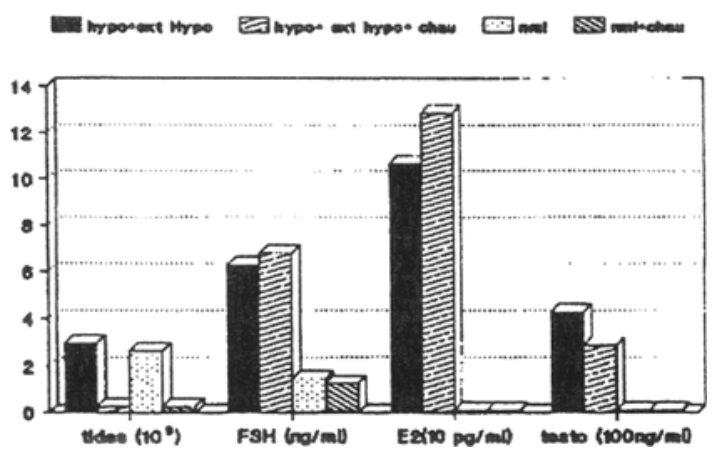


concentration en testostérone dans le plasma périphérique est abaissée après chauffage scrotal (70 et $30 \%$ respectivement chez les béliers normaux ou hypo/ext.h). Les concentrations en œstrogène dans le plasma périphérique ou veineux testiculaire ne sont pas modifiées.

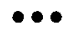

\section{ABSENCE DE REGULATION NEGATIVE DES ARN MESSAGERS DU RECEPTEUR A LA FSH DANS LES BIOPSIES TESTICU- LAIRES DE PATIENTS PRESENTANT UN TROUBLE DE LA SPERMATOGENESE}

\author{
H. Lejeune*, C. Brebant* P. Cousin* N.Ber- \\ Ger-DutrieuX*, M. DevoneC ${ }^{\circ}$, M. Pugeat* \\ * Clinique Endocrinologique, \\ ** Laboratoire d'Anatomo-pathologie \\ 'Service d'Urologie, Hôpital de l'Antiquaille \\ Lyon, France. (Réseau INSERM n 493010)
}

\section{Introduction}

Dans le but de mieux comprendre la physiopathologie des troubles de la spermatogenèse, nous avons développé une méthode de mesure des ARN messagers (ARNm) dans les biopsies testiculaires par RT-PCR (Andrologie, 1996 ; 6 : 214223). Cette méthode a été appliquée à la mesure des ARNm de la Protamine-1, gène spécifiquement exprimé dans les spermatides, relativement aux ARNm de la $\beta$-actine et à la mesure des $\mathrm{ARNm}$ du récepteur à la $\mathrm{FSH}$, par rapport aux ARNm de la Clusterine, gène marqueur des cellules de Sertoli, sur des biopsies testiculaires obtenues chez des patients présentant une infertilité avec des atteintes diverses de la spermatogenèse.

\section{Matériel et méthodes}

Cette étude préliminaire porte sur 10 biopsies testiculaires obtenues chez 7 patients présentant une infertilité. Trois patients ont eu une cure chirurgicale de varicocèle. Une biopsie des deux testicules a été étudiée. Quatre patients azoospermiques présentaient des aspects histologiques identiques sur les biopsies des deux testicules. Une seule biopsie a été étudiée, L'azoospermie était sécrétoire pour un patient, excrétoire pour 3 patients. Le volume testiculaire a été déterminé à l'aide d'un orchidomètre de Prader, la concentration plasmatique de FSH a été mesurée par méthode radioimmunologique. L'aspect anatomopathologie a été analysé en utilisant la classification de Valette. Le score T de cette classification cote de 1 à 12 l'intensité des altérations de la spermatogenèse.

Un fragment de parenchyme testiculaire a été fixé dans le liquide de Bouin pour l'étude anatomopathologique, un autre fragment a été congelé et conservé dans l'azote liquide jusqu'à l'extraction des ARN. L'extraction des ARN totaux a été réalisée par une modification de la méthode de Chomczynski et Sacchi, après broyage au polytron des fragments de parenchyme testiculaire congelés. La méthode utilisée permet d'obtenir 1,0 $\pm 0,1 \mathrm{mg} \mathrm{d}^{\prime} \mathrm{ARN}$ total/mg de tissu frais (m- \pm lds $; n=15$ ).

La transcription inverse a été réalisée à partir d'l mg d'ARN total en utilisant une amorce oligodT. L'amplification par PCR est conduite sur les produits de RT correspondant à $0,1 \mathrm{mg}$ d'ARN total. Les amorces de PCR ont été choisies sur des exons différents. Leur composition similaire (20-mer ; 45-551\% CG) permet une amplification avec des conditions de températures identiques pour tous les gènes $\left(1 \min 3094^{\circ} \mathrm{C}-2 \min 55^{\circ} \mathrm{C}\right.$ $3 \min 72^{\circ} \mathrm{C}$ ). Une co-amplification du cDNA d'intérêt et du cDNA de référence est réalisée dans le même tube. La révélation des produits de PCR a été réalisée par Southern blot avec électrophorèse en gel d'agarose $1 \%$, transfert sur membrane de nylon, hybridation avec les sondes de cDNA spécifiques marquées au 32p-CTP par random priming, lavage à haute stringence, autoradiographie, densitométrie et calcul du rapport des mesures en phase exponentielle d'amplification. Nous avons montré que cette méthode est en bonne corrélation avec les résultats des Northern blots.

\section{Résultats}

On observe une corrélation significative entre les ARNm de la protamine-1, rapportés aux ARNm de la $\beta$-actine, et le score $T$ de la classification de Valette : $r=0,894 ; p=0005 ; n=10$, le volume testiculaire : $r=0,864 ; p=0,0013 ; n=10$, et la concentration plasmatique de FSH : $\mathrm{r}=0,87 ; \mathrm{p}=0,0108 ; \mathrm{n}=7$.

Par contre les ARNm du récepteur à la FSH, rapportés aux ARNm de la Clusterine, ne sont pas en corrélation avec le score $\mathrm{T}$ de Valette, le volume testiculaire, ou la concentration plasmatique de FSH. 


\section{Discussion}

L'étude des ARNm de la protamine-1 montre que la méthode de mesure des ARNm par RTPCR dans les biopsies testiculaires est en bonne corrélation avec les données anatomopathologiques. L'étude des $\mathrm{ARNm}$ du récepteur à la FSH ne supporte pas l'hypothèse d'une régulation négative des ARNm du récepteur à la FSH lors de l'élévation chronique de la FSH dans les troubles de la spermatogenèse.

\section{PROTEINES DE LIAISON A L'ACTINE DANS LE TESTICULE HUMAIN}

\author{
R. Rousseaux-Prevost*, B. Delobel*, J.M. \\ RIGOT $^{*}, * *$, E. HERMAND ${ }^{\circ}$, P. DANJOU ${ }^{\circ}$, E. MAZEMAN ${ }^{* *}$, \\ J. RoUSSEAUX* \\ * EA 1719, IRCL, Lille, \\ ** Service d'Urologie, CHRU, Lille, \\ - Laboratoire de Cytologie et Biologie de la \\ Reproduction, CHRU Lille, \\ ${ }^{\circ}$ Service d'Urologie CH Lens.
}

\section{Introduction}

Le tube séminifêre est une architecture anatomique complexe composée de cellules myoïdes péritubulaires entourant un épithélium où s'intriquent cellules germinales et cellules de Sertoli. De nombreux remaniements morphologiques se produisent dans cet épithélium au cours de la différenciation des cellules germinales.

L'objectif général de notre travail est de définir le rôle joué par l'actine et les protéines de liaison à l'actine dans la dynamique d'organisation du tube séminifêre.

Nous présentons ici l'identification et la localisation immunocytochimique, dans le testicule humain, de protéines de liaison à l'actine impliquées dans les processus contractiles.

\section{Matériels et Méthodes}

Les protéines ont été caractérisées par la technique de Western Blot dans des extraits obtenus à partir de testicule entier ou provenant de suspensions cellulaires.

La distribution des protéines dans le testicule a été définie par immunofluorescence indirecte sur des coupes au cryostat.

\section{Résultats}

L'actine, la gelsoline, la myosine (muscle lisse) et la tropomyosine sont mises en évidence dans les protéines extraites de broyats testiculaires, alors que dans des suspensions cellulaires contenant essentiellement cellules germinales et cellules de Sertoli, on ne retrouve que la présence de gelsoline et d'actine. En immunocytochimie réalisée sur des testicules normaux, les cellules myoïdes péritubulaires apparaissent contenir l'actine (isoforme alpha de muscle lisse), la myosine, la tropomyosine et la gelsoline. Actine et gelsoline sont aussi concentrées dans l'épithélium séminifêre près de la lumière du tubule. Une répartition identique de ces protéines a été retrouvée dans une étude préliminaire de biopsies testiculaires provenant de patients présentant une altération de la spermatogenèse.

\section{Discussion}

La présence d'actine, de myosine, de tropomyosine, de gelsoline dans les cellules péritubulaires est en accord avec le caractère myoïde de ces cellules. La concentration de la gelsoline, avec l'actine, à la surface de l'épithélium séminifère,y compris en absence de lignée germinale, montre que cette protéine est localisée à l'apex des cellules de Sertoli. Sa fonction pourrait être de faciliter les processus de sécrétion et de réabsorption des macromolécules ou la production du fluide tubulaire. Une étude est actuellement en cours afin de définir si certains cadres d'oligospermie ou d'azoospermie peuvent s'accompagner d'une altération d'expression de ces différentes protéines.

\section{"L'ASCENSION INCONSTANTE DU TESTI- CULE" EST UN FACTEUR DE RISQUE POTENTIEL POUR LA SPERMATOGENE- SE DES HOMMES INFECONDS}

\author{
R. Mieusset*, L. E. BuJaN*,**, G. MASsaT*, A. \\ MANSAT $^{* *}$, F. PONTONNIER*,** \\ * Centre de Stérilité Masculine \\ ** CECOS-Midi-Pyrénées, CHU La Grave, \\ 31052 Toulouse, France.
}

\section{Introduction}

La position normale des testicules est une localisation scrotale. L'objectif de l'étude était d'évaluer un éventuel effet de la localisation des testicules sur les paramètres du sperme d'hommes inféconds. 


\section{Matériel et méthode}

Etude rétrospective portant sur 85 hommes féconds et 914 hommes ayant consulté pour une infécondité et ne présentant aucun antécédant de cryptorchidie ou d'ectopie testiculaire. Anamnése et examen clinique (température ambiante : 20 $25^{\circ} \mathrm{C}$ ) incluant mesure des volumes testiculaires et recherche d'un varicocèle clinique. La position des testicules est enregistrée (basse ou haute). On note l'existence d'une localisation supra-scrotale des testicules (en indiquant cette localisation au patient), en dehors des situations habituelles où une telle localisation peut être observée (érection, bains froids ...). L'analyse de sperme comprend numération et mobilité (au microscope) des spermatozoïdes.

Le premier éjaculat suivant l'examen clinique est seul retenu pour cette étude. La survenue régulière d'une position supra-scrotale d'un testicule habituellement en position scrotale est appelée "ascension testiculaire inconstante". Les moyennes sont comparées par le Mann-Whitney $\mathrm{U}$, les pourcentages par le chi 2 . Les odd ratios sont calculés avec EPITM.

\section{Résultats. Discussion}

La fréquence d'au moins un testis en situation scrotale haute est semblable chez les hommes féconds $(\mathbf{1 6 , 5 \% )}$ et inféconds $(17 \%)$. Bien que sans effet sur les caractéristiques du sperme, cette position intrascrotale haute du testicule pourrait ne pas être qu'un variant physiologique. En effet, une ascension testiculaire inconstante survient plus fréquemment en cas de testicule haut situé. La fréquence de cette ascension testiculaire inconstante n'est pas significativement différente chez les féconds $(11,8 \%)$ et les inféconds $(18,3 \%)$.

Cependant, les hommes inféconds ayant une ascension testiculaire inconstante ont une spermatogénése plus altérée que les hommes inféconds ayant des testicules en situation scrotale permanente, avec une réduction de la quantité totale de spermatozoïdes $(80,7 \pm 116,8$ versus $118,8 \pm 83,6 \times 106 / e j a c u l a t ; p<0,006)$ et du pourcentage de spermatozoides mobiles $(25,9 \pm 25,9$ versus $30,4 \pm 18,5 \% ; p<0,009)$. Cette altération de la spermatogenèse est retrouvée aussi bien en présence ou en absence d'un varicocéle clinique. Enfin, l'ascension testiculaire inconstante n'est pas associée à une réduction significative des volumes testiculaires.

\section{QUALITE DU SPERME ET DES SPERMATOZOIDES}

\section{METHODES D'EVALUATION ET MARQUEURS}

\section{EVALUATION DE LA QUALITE DU SPER- ME DE PATIENTS FERTILES EN SLOVE- NIE PENDANT LA PERIODE 1983-1995}

\author{
E. Zorn, I. VIRANT-KIUN, C. VJETICANIN., H. \\ Meden-VRtovec, T. Tomazevic \\ Service de gynécologie-obstétrique, \\ Centre clinique universitaire,Ljubljana, Slovénie
}

\section{Introduction}

Ces dernières années, plusieurs études dans le monde rapportent une qualité moindre du sperme humain. Ces études émanent tant de métaanalyses utilisant les données de plusieurs centres répartis sur plusieurs continents avec des critères de recrutement variables que de centres d'andrologie distincts utilisant des méthodes d'analyse bien codifiées sur des populations homogènes faites en général de donneurs de sperme.

C'est Carlsen en 1992 qui dans une métaanalyse répertoriant 61 études met en évidence une détérioration des paramètres du spermogramme des hommes fertiles entre 1940 et 1990 . Une semblable diminution de la concentration, de la mobilité et des formes normales des spermatozoïdes a été rapportée par Auger dans la région parisienne, par Irvine en Ecosse et d'autres auteurs en particulier à Londres et en Belgique. Ce phénomène ne semble cependant pas universel. Aux Etats Unis d'Amérique, deux études indiquent qu'il n'y a aucune modification de la qualité du sperme ; au contraire, la tendance serait à la hausse. Une constatation identique prévaut en Finlande. En France, on a identifié des différences à l'intérieur du pays : bonnes concentra. tions à Toulouse et à Lille par exemple, mauvais paramètres à Paris. Jusqu'à présent, nous ne disposions pas de données émanant de pays d'Europe Centrale ou de l'Est. Nous rapportons certaines informations concernant la SLOVENIE.

Le but du travail a été de déterminer les éventuelles modifications de la qualité du sperme pendant la 
période 1983-1995 chez des hommes au sperme normal inclus dans le programme de fécondation in vitro à la clinique gynécologique de Ljubljana.

\section{Méthodes}

Nous avons réuni et analysé les données de l'examen du sperme (volume, concentration, mobilité et morphologie) dans 2 groupes d'hommes au spermogramme normal selon les critères de l'OMS. Le groupe 1 est constitué de 1085 hommes au spermogramme normal partenaires de femmes atteintes exclusivement d'un facteur tubaire de stérilité qui ont été enceintes à la suite de la tentative de FIV. Le groupe 2 est fait de 800 hommes au spermogramme normal partenaires de femmes atteintes de facteur tubaire exclusif mais qui n'ont pas été enceintes après la tentative de FIN. Pour l'analyse statistique, nous avons utilisé la régression linéaire tenant compte de l'âge du patient, de l'abstinence et du volume de l'éjaculat.

Les résultats préliminaires ont montré que la concentration des spermatozoïdes durant la période étudiée accuse une décroissance tandis que le volume et la mobilité semblent stables. Surtout dans les 2 groupes, cette concentration a chuté plus fortement pendant la période 1989-1991.

\section{Conclusion}

Nous avons observé dans nos populations d'hommes au spermogramme normal une chute de la concentration des spermatozoïdes pendant la période 1983-1995 avec aggravation ponctuelle entre 1989-1991. On apprendra sans surprise que pendant cette période la Slovénie a connu des remous politiques sans précédent. Le stress, facteur environnemental de première importance, peut-il expliquer ces variations?

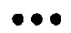

\section{MESURE ET ROLE DU PH INTRACELLU- LAIRE DANS LA MOBILITE DU SPERME HUMAIN}

\author{
S. HamamaH*, E. Magnoux*, D. Royere*, C. \\ BARTHELEMY*, J-L. GATTI** \\ * Unité de Biologie de la Reproduction, Dept de \\ Gynéco-Obs, Faculté de Médecine, \\ CHU Bretonneau, F-37044, Tours, \\ ** URA INRA-CNRS 1291, INRA-Station de \\ Physiologie de la Reproduction des Mammifêres \\ Domestiques, 37380 Nouzilly
}

Le $\mathrm{pH}$ intracellulaire (pHi) joue un rôle dans la mobilité et dans l'induction de la réaction acrosomique des spermatozoïdes de mammifères. Plusieurs facteurs ayant des effets stimulants sur les spermatozoïdes ont été purifiés dans le liquide folliculaire humain (HFF). Parmi ceux-ci l'albumine, les glycosaminoglycanes, et surtout la progestérone. La progestérone comme la $17 \alpha-$ hydroxy-progestérone peuvent stimuler et induire la réaction acrosomique des spermatozoïdes. Afin de déterminer quel est le rôle du pHi dans 1e fonctionnement des spermatozoïdes humains, cette étude a eu pour but :

- de mettre au point une méthode fiable afin d'évaluer le pHi dans les spermatozoïdes,

- d'étudier la régulation du pHi en particulier l'effet $\mathrm{du} \mathrm{pH}$ extracellulaire ( $\mathrm{pHe}$ ) et des cations tels que $\mathrm{Na}+$ et $\mathrm{K}+$,

- d'analyser l'effet du HFF et de la progestérone sur le pHi des spermatozoïdes,

- et d'étudier l'effet du pHe sur la mobilité.

\section{Matériels et Méthodes}

Les spermatozoïdes de patients $(n=54)$ participant à une tentative de FIV ont été lavés puis incubés dans deux milieux de culture contenant soit du sodium (NaM) soit du potassium (KM) comme ion principal et tamponés a différents $\mathrm{pH}$ externes $(7,2 ; 7,4 ; 7,8$ et 8,2$)$. Le pHi des spermatozoïdes a été mesuré par une sonde radioactive la $\mathrm{C} 14$-méthylamine et par une sonde fluorescente (BCECF). Le pHi des spermatozoïdes a été mesuré avant et après préparation sur un gradient de Percoll. Les valeurs ont été exprimées en termes de moyenne \pm SD.

\section{Résultats}

Dans les deux milieux, la valeur du pHi a été inférieure de 0,4 à 0,6 unité à celle du pHe.

Une relation linéaire entre $\mathrm{pHe}$ et $\mathrm{pHi}$ existe. Cette relation indique que le pHi des spermatozoïdes dépend principalement du pHe. L'addition de $10 \mathrm{mM}$ de progestérone à des spermatozoïdes incubés à $\mathrm{pH} 7,2$ ne produit pas de variation de l'intensité de fluorescence $d u$ BCECF. Il n'y a donc pas de changement de pHi apparent avec cette sonde. Par contre, lorsque l'effet de 1a progestérone est mesuré par l'accumulation de méthylamine, il semble qu'une légère augmentation du $\mathrm{pHi}$ de 0,2 unité se produit. L'addition de $10 \mathrm{mM}$ de $17 \beta$ - 
oestradiol comme le HFF produit une très légère diminution de fluorescence et donc du pHi. Cette variation est d'environ 0,05 unité $\mathrm{pH}$. Le pHi des spermatozoïdes préparés sur Percoll est légèrement inférieur d'environ 0.2 unité à celui des spermatozoïdes simplement lavés.

\section{Discussion et Conclusion}

Cette étude montre qu'il est possible de mesurer le pHi des spermatozoïdes de façon fiable et répétitive malgré la grande hétérogénéité du sperme humain. Une relation quasi-linéaire existe entre le $\mathrm{pHi}$ et le $\mathrm{pHe}$ du milieu de culture. Il n'a pas été observé d'effet significatif du HFF et du $17 \beta$-oestradiol sur le pHi des spermatozoïdes. Par contre, la progestérone induit une augmentation du pHi de spermatozoïdes. Il ne semble pas qu'il y ait de relation entre l'augmentation du calcium intracellulaire et le $\mathrm{pHi}$ des spermatozoïdes sous l'effet de 1a progestérone. Le fait qu'on puisse maintenant évaluer le pHi du sperme humain de façon fiable et répétitive, devrait nous permettre son évaluation en cas d'asthénozoospermie, car on oublie souvent que le pHi avec le calcium intrace1lulaire et l'AMPc est l'un des facteurs importants qui régulent la mobilité des spermatozoïdes.

$\bullet \bullet$

\section{ACIDE HYALURONIQUE SEMINAL ET POURCENTAGE D'ACROSOMES MALFORMES}

\author{
A. Laudat*, J. Guechot**, P. Foucault ${ }^{*}$, A-M. \\ Palluel * \\ * Laboratoire de Biochimie-Biologie de la Repro- \\ duction, C.H.G. de Chartres, 4, rue C. Bernard, \\ 28630 Chartres \\ ** Laboratoire de Biochimie-Hormonologie, \\ Hôpital Saint-Antoine, 184, rue du faubourg \\ Saint-Antoine, 75571 Paris cedex 12
}

\section{Introduction-But}

Quelques travaux rapportent la présence d'un marqueur de la matrice extracellulaire, l'acide hyaluronique $(\mathrm{AH})$, au sein du liquide séminal. L'AH plasmatique, polymère linéaire constitué par l'enchaînement d'unités disaccharidiques ( ... [D-acide glucuronique (1-b-3) N-acétyl-D-glu- cosamine 1-b4)]n ... ), est synthétisé par les cellules des membranes basales, relargué par les tissus et métabolisé par les cellules endothéliales hépatiques. Le but de cette étude était de doser l'AH dans le plasma séminal de 35 patients afin d'évaluer l'éventuelle corrélation entre ce composé et le pourcentage d'acrosomes malformés.

\section{Matériel et méthodes}

Au décours d'un spermogramme, l'AH a été quantifié dans le plasma séminal de 35 patients (m \pm DS : âge : $33,2 \pm 5,9$ ans ; volume de l'éjaculat: $4,2 \pm 1,7 \mathrm{ml} ; \mathrm{pH}: 7,7 \pm 0,2$; abstinence sexuelle : $3,7 \pm 1,4$ jours). Le spermocytogramme a consisté en l'observation de 100 spermatozoïdes en contraste interférentiel différentiel à l'objectif x100 à immersion après coloration par la technique de Harris-Shorr. La détermination des concentrations en $\mathrm{AH}$ séminal a été réalisée par une technique du type radiométrique séquentielle basée sur l'utilisation de protéines isolées de cartilages d'origine bovine fixant spécifiquement l'AH.

\section{Résultats-Discussion}

L'AH a pu être déterminé dans la totalité des prélèvements $(349 \pm 164 \mathrm{mg} / \mathrm{l})$. L'analyse par le test de Spearman a montré une corrélation positive, statistiquement significative, entre les concentrations en $\mathrm{AH}$ séminal et le pourcentage d'acrosomes malformés ( $p<0,01 ; r=+0,5$ ). Aucune corrélation n'a été mise en évidence entre l'AH séminal et les 6 autres anomalies possibles de la tête des spermatozoïdes (allongée, amincie, base amincie, microcéphale, macrocéphale, dupliquée).

Nos résultats semblent indiquer une certaine participation des spermatozoïdes au métabolisme de l'AH séminal, soit dans le sens de la synthèse, soit du catabolisme, notamment par l'action de la hyaluronidase présente au niveau de l'acrosome. De plus, le fait que le pourcentage d'acrosomes malformés augmente avec l'élévation des concentrations en $\mathrm{AH}$ séminal semble montrer que ce composé puisse être un marqueur indirect de ce type d'anomalie cytologique. 


\section{ANTICORPS ANTI-SPERMATOZOIDES ET PARAMETRES DU MOUVEMENT DANS LES INFERTILITES MASCULINES}

\section{S. Pilikian, R. Levy, M. Benchaib, G. Pitayal, J.F. GUERIN \\ Laboratoire de Biologie de la Reproduction, Hôpital Edouard-Herriot, Lyon}

\section{Introduction}

La présence d'Ac anti-spermatozoïdes (ACAS) peut exercer un effet adverse sur la migration des spermatozoïdes dans la glaire [1], la capacité de fusion avec l'ovocyte [2], la fécondation in vitro [3], ainsi que sur le mouvement des spermatozoïdes selon le degré d'immunisation et la nature des ACAS $[4,5]$.

Chez les sujets consultant pour infertilité nous avons recherché la présence des ACAS agglutinants dans le sperme, le plasma séminal et le sérum et nous avons comparé les paramètres de mobilité des spermatozoïdes en présence et en l'absence d'ACAS fixés ou circulants.

\section{Matériel et Méthodes}

L'étude porte sur l'analyse du sperme de 90 sujets présentant une infertilité. Les examens suivants ont été effectués sur les spermatozoïdes dans l'éjaculat et après migration sur un gradient du Percoll :

- analyse automatisée du mouvement par le Cell Soft ( $\mathrm{n}=90)$

- recherche des ACAS fixés (MAR test $n=80$ et IBtest lorsque le MAR test était positif)

- recherche des ACAS circulants dans le plasma séminal et le sérum $(n=80)$.

\section{Résultats-Discussion}

Près d'un tiers des sujets (25/80) présentent des ACAS fixés sur les spermatozoïdes ; il existe également une corrélation positive entre les anticorps fixés et la présence d'ACAS circulants dans le plasma séminal et le sérum.

En ce qui concerne les paramètres du mouvement en présence ou absence d'ACAS, aucune différence significative n'a pu être mise en évidence pour la vitesse curvilinéaire, l'amplitude du déplacement latéral de la tête et le pourcentage d'hyperactivation des spermatozoïdes aussi bien dans l'éjaculat qu'après selection sur Percoll. La seule différence significative due aux
ACAS fixés concerne la vitesse de progression des spermatozoïdes dans le plasma séminal (49 $\mathrm{mm} / \mathrm{sec}$ versus $55 \mathrm{~mm} / \mathrm{sec}$ en l'absence d'ACAS, $\mathrm{p}<0.05$ ), toutefois cette différence disparaît après traitement au Percoll.

Ces résultats suggèrent que la présence d'ACAS fixés n'altère pas significativement les paramètres du mouvement et que le défaut de fécondation doit être expliqué par un mécanisme membranaire dû à la présence même des ACAS.

\section{BIBLIOGRAPHIE}

1. MATHUR S. et al. : Fertil. Steril. 1984,41,81.

2. ALEXANDER N.J. : Fertil. Stéril. 1984, 41,433.

3. CLARK G.N. et al. : AJRIM 1985, 8,62.

4. WOLF J.P. et al. : Fertil.Steril. 1995,63,584.

5.- MATHUR S.et al. : AJRIM 1986, 12, 87.

\section{COMPARAISON ENTRE LA CYTOMETRIE EN FLUX DU TISSU TESTICULAIRE ET LES ALTERATIONS DE LA SPERMATO- GENESE CHEZ LES PATIENTS HYPOFER- TILES A RISQUE DE CARCINOME IN SITU DU TESTICULE}

\author{
L. SIBERT'* N. RIVES ${ }^{* *}$, F. GOBET ${ }^{\circ}$, E. BARRET*, \\ C. PfISTER*, B. MACE** \\ * Service d'Urologie, CHU Rouen, Hôpital \\ Charles-Nicolle, 76031 Rouen cedex \\ ** Laboratoire d'Histologie, CHU Rouen, 76031 \\ Rouen cedex \\ *** Laboratoire d'Anatomie Pathologique, $\mathrm{CHU}$ \\ Rouen, 76031 Rouen cedex
}

\section{Introduction}

Le but de cette étude à été de comparer l'importance des altérations de la spermatogénèse et les données de la cytométrie en flux réalisée sur tissu testiculaire sur un échantillon de patients suivis pour hypofertilité et présentant un risque élévé de carcinome in situ (CIS) du testicule.

\section{Matériel et Méthode}

Parmi plus de 150 patients consultant pour hypofertilité, 15 patients ont subi outre un spermocytogramme, une biopsie testiculaire chirurgicale dont l'indication était justifiée par le bilan clinique et biologique. Sur chaque prélèvement 
testiculaire ont été réalisés un examen histologique classique permettant de statuer sur la spermatogénèse et de rechercher des lésions de CIS, et une étude en cytométrie de flux (sur bloc paraffiné selon la technique de Hedley, coloration à l'iodure de propidium, appareils Coultronics, logiciel Software).

\section{Résultats}

8 patients étaient cryptorchides, 2 avaient un séminome testiculaire, 5 patients avaient un examen clinique normal. 4 patients avaient une oligospermie, tous les autres avaient une azoospermie. L'examen histologique a révélé un CIS, il était normal chez les autres patients. Il y avait un arrêt de la spermatogénèse chez 14 patients et un arrêt de la maturation (spermatocyte I) chez le patient avec des lésions de CIS.

En cytométrie de flux, le patient avec GIS présentait un pic péritétraploïde avec un index de prolifération élévé, les 14 autres patients présentaient une disparition du pic cellulaire haploïde correspondant à la population cellulaire germinale normale.

\section{Conclusion}

Une étude préliminaire préalable a montré qu'il existait des anomalies cytométriques sur le sperme des patients exposés au risque de CIS.

Cette étude complémentaire confirme, sur une faible population, l'intérêt de la cytométrie en flux dans l'appréciation et la quantification des altérations de spermatogénèse et la possibilité d'anomalies cytométriques en plus grande proportion chez les patients présentant des lésions histologiques évocatrices de CIS.

$\bullet \bullet$

\section{DETECTION DES DISOMIES DES CHRO-} MOSOMES 4, 5, 6, 9, 13, 14, 20, 21, 22, DANS LES SPERMATOZODES HUMAINS A L'ADE DE SONDES DE PEINTURE CHROMOSOMIQUE

\footnotetext{
N. Rives*, S. Mazurier*, V. Duchesne*, D. Bellet* G. Joly*, L. Sibert**, B. Mace*

* Laboratoire d'Histologie, CHU Charles Nicolle, 76031 Rouen cedex

** Service d'Urologie, CHU Charles Nicolle, 76031 Rouen cedex
}

L'hybridation in situ à l'aide de sondes de séquences alphasatellites centromériques et le PRINS (PRimed IN SITU) constituent des alternatives dans l'étude des aneuploïdies des spermatozoïdes humains, à l'analyse des caryotypes obtenus après fécondation hétérospécifique homme-hamster. Ces techniques ont une bonne sensibilité, cependant l'existence d'homologie entre les séquences d' ADN centromérique de certains chromosomes diminue leur spécificité. Le but de notre travail a été d'étudier les disomies des spermatozoïdes de sujets normalement fertiles à l'aide de sondes de peinture chromosomique sachant que cette approche permet une analyse spécifique de chaque chromosome.

\section{Matériels et Méthodes}

\section{a) Préparation des spermatozoüdes :}

Les éjaculats provenants de 4 sujets fertiles aux paramètres spermatiques normaux (définis par l'OMS), âgés entre 25 et 42 ans sont liquéfiés à $37^{\circ} \mathrm{C}$ pendant $20^{\prime}$, lavés dans le PBS et fixés dans un mélange de méthanol : acide acétique (3 :1) avant étalement sur lames.

\section{b) Préparation des sondes :}

Les sondes de peinture (STAR *FISH, Cambio Biosys $\left({ }^{(}\right)$des chromosomes 5,14, 21, 22 sont couplées au FITC et des chromosomes 4, 6, 9, 13 et 20 sont biotinylées. Elles subissent une dénaturation à $65^{\circ} \mathrm{C}$ avant une étape d'annealing à $37^{\circ} \mathrm{C}$ pendant 60 minutes.

\section{c) Hybridation in situ :}

L'ADN des spermatozoïdes est décondensé dans $\mathrm{du}$ D'TT $25 \mathrm{mM}$ TrisHcl $\mathrm{lM}$ pH9,5, puis dénaturé à $73^{\circ} \mathrm{C}$ dans du SSC 2X, formanide $70 \% \mathrm{pH} 7$. L'hybridation en double marquage s'effectue à $37^{\circ} \mathrm{C}$ pendant 24 heures.

\section{d) Révélation et analyse des résultats :}

Anticorps anti FITC (FITC) - Avidine/Anticorps anti-avidine (Texas Red).

L'observation s'effectue à l'aide d'un microscope à fluorescence DMRD (LEICA, avec un filtre double bande. L'homogénéité des disomies pour chaque chromosome chez un sujet donné et entre les sujets a été vérifiée par le test du $\chi^{2}$.

\section{Résultats}

Le taux de marquage des noyaux atteint $99 \%$. Le nombre de noyaux analysés par sujet et par 
chromosome est en moyenne de 6.509. Un total de 130.180 spermatozoïdes a été étudié. La fréquence de disomie pour le chromosome 4 est de $0,23 \%, 5$ de $0,20 \%, 6$ de $0,28 \%, 9$ de $0,26 \%, 13$ de $0,20 \%, 14$ de $0,21 \%, 20$ de $0,23 \%, 21$ de $0,23 \%$, 21 de $0,19 \%, 22$ de $0,27 \%$.

Aucune différence significative n'a été observée pour chaque chromosome entre les sujets et pour les différents chromosomes chez un même sujet et entre les sujets.

\section{Conclusion}

L'hybridation in situ à l'aide de sondes de peinture chromosomique constitue un moyen d'étude spécifique des aneuploïdies des spermatozoïdes. Pour les premiers chromosomes étudiés, on note une uniformité du taux de disomie $(0,23 \%)$ qui tend à conforter l'hypothèse d'une répartition équiprobable des non disjonctions dans le sexe masculin.

\section{QUALITE DU SPERME ET STRATE- GIE D'AMP}

\section{PLACE ET VALEUR DU TEST POST- COITAL DANS L'INVESTIGATION DU FACTEUR MASCULIN DES COUPLES ADMIS EN PROCREATION MEDICALE- MENT ASSISTEE}

Y. SOFFER*, S. KAUFMAN*, A. RAZIE*,**, S. FRIED-

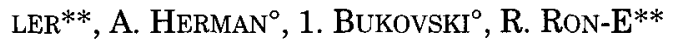

* Centre de Fertilité Masculine et Unité de FlV, ** Service d'Obstétrique et de Gynécologie, *** Centre Médical Assaf Harofé, Faculté de Médecine Sackler ; Université de Tel Aviv. Israël

\section{Introduction}

Dans une unité de procréation médicalement assistée (PMA), il est souvent nécessaire de faire une analyse fine du pouvoir fécondant des spermatozoïdes ( $\mathrm{spz}$ ) chez des couples infertiles afin de choisir le mode adéquat de PMA, inséminations endo-utérines, FIV ou fécondation assistée (ICSI). A cause du caractère multifactoriel de la qualité du sperme et de son pouvoir fécondant, les examens nécessaires sont nombreux, souvent coûteux et compliqués. Le test post-coïtal (PCT) est un examen clinique fort simple. A-t-il encore une place, de nos jours, dans la batterie des investigations masculines en PMA?

\section{Objectifs}

Analyser dans une étude prospective, la relation du PCT avec l'examen du sperme, le confronter avec les épreuves fonctionnelles in vitro des spz et démontrer sa valeur prédictive dans l'analyse fine de leur qualité et de leur pouvoir fécondant.

\section{Matériel et Méthodes}

Dans un groupe de 338 couples de PMA, le PCT a été pratiqué après 8 à $18 \mathrm{~h}$ d'attente, dans une glaire cervicale optimale. Une anamnèse des grossesses récentes du couple a été aussi obtenue. Des examens de sperme, des tests immunologiques (SpermMar IgA et IgG) et des épreuves fonctionnelles, épreuves du hamster (SPA) et de l'hémizone (HZA) ont été faits chez les conjoints. L'analyse statistique a comparé :

- Le PCT a l'examen du sperme (index de mobilité (IM), compte total (CT), \% de formes strictement normales (FN) et anticorps IgA et IgG).

- le PCT aux épreuves fonctionnelles in vitro (SPA et HZA).

- Le PCT et tous les examens andrologiques au taux d'ovocytes fécondés, à la qualité des embryons et aux grossesses obtenues à la suite d'un ou de plusieurs cycles de FIV ( 2 en moyenne) et souvent d'ICSI pratiqués chez ces couples.

Cette investigation statistique s'est fondée sur l'analyse de variance, le test du chi-au-carré et l'analyse multifactorielle.

\section{Résultats}

Comparé à l'examen de sperme de routine en analyse multifactorielle (Test $\mathrm{F}$ significatif, si $\mathrm{F}>4)$, le PCT corréle avec IM $(\mathrm{F}=-43.7)$ et $\mathrm{CT}(\mathrm{F}=$ 29.2), mais pas avec $\mathrm{FN}(\mathrm{F}=2.4)$. Il corrèle avec la présence d'auto-anticorps sur les $\mathrm{spz}(\mathrm{F}=9.1)$, de la classe des IgA bien plus que des IgG.

Comparé aux épreuves fonctionnelles, il corrèle bien avec SPA ( $\mathrm{F}=12.8)$, mal avec HZA ( $F=-3 . d)$ et surpasse vis-à-vis de ces épreuves, IM, CT et anticorps.

Dans l'analyse mulifactorielle des facteurs prédictifs de la fécondation, les variables les plus 
significatives sont, dans l'ordre, SPA, PCT, HZA, bien avant $\mathrm{FN}$ ou les autres variables du sperme. Iorsque l'on adjoint au PCT l'anamnèse clinique des grossesses récentes (oui ou non), sa valeur prédictive s'accentue.

\section{Conclusion}

Le test post-coïtal, PCT, est un examen simple qui ne nécessite aucun équipement spécial de laboratoire ; et pourtant, convenablement fait, il n'en reste pas moins en cette ère d'ICSI, face aux examens in vitro disponibles mais sophistiqués et coûteux, une épreuve fonctionnelle très utile qu'il ne faudrait pas négliger.

\section{$\bullet \bullet$}

\section{ANNEES D'INSEMINATIONS INTRA- UTERINES AVEC SPERME DU CONJOINT (IIU-AC) : QUELLES CONCLUSIONS EN TIRER}

\author{
O. Paulmyer-Lacrotx, L. Molle, A. Noizet, A. \\ Gutrin, M. Mollar, M. Gamerre, J.M. Grillo
}

Hôpital de la Conception, Laboratoire de Biologie de la Reproduction, 147 Bd Baille 13005 Marseille

Cette étude rétrospective porte sur 936 IIU-AC (384 couples) effectuées entre janvier 1991 et octobre 1995 au CHU de la Belle de Mai.

\section{Matériel et Méthodes}

\section{a) Indications :}

- Anomalies du spermogramme associées ou non à un problème féminin ;

- Pathologie féminine isolée (dysovulation, pathologie cervicale, anomalie tubaire unilatérale) ;

- Infertilité inexpliquée.

\section{b) Après stimulation quasi systématique} (par anti-estrogènes ou par gonadotrophines) et monitorage de l'ovulation l'IIU a été pratiquée 36 à $40 \mathrm{H}$ après le déclenchement de l'ovulation par HCG 5000 UI.

Le sperme a été inséminé dès la fin de la préparation par centrifugation sur gradient de Percoll (CGP) $(0.15 \mathrm{ml})$. Le nombre de spermatozoïdes mobiles obtenus après CGP ainsi que leur survie à $24 \mathrm{H}$ ont été appréciés.

\section{Résultats}

107 grossesses (Taux de grossesse/ cycle (TG/C) : $11.4 \%)$; naissance de 86 enfants.

Notre étude montre que les chances de succès diminuent avec l'âge de la patiente (de façon nette après 38 ans) avec la durée de l'infertilité (nettement après 8 ans) et après 4 cycles d'IAC.

La stimulation de l'ovulation entraîne un meilleur TG/C par rapport aux cycles non stimulés $\left(11.5 \%\right.$ vs $\left.5.5^{\circ} \%\right)$. Les TG/C sont comparables sous anti-E2 ou sous HMG, sauf dans les cas de dysovulation où on note une amélioration du TG/C sous HMG ( $20.8 \%$ vs $12.5 \%$ sous anti-E2). Par ailleurs, seuls 3 syndromes d'hyperstimulation ovarienne sévères et 6 grossesses multiples (5 gémellaires et 1 quadruple) ont été rapportés.

Les meilleurs TG/C ont été obtenus dans les stérilités par dysovulation $(15.6 \% ; 7 \%$ de nos indications) dans les stérilités d'origine masculine $(11,7 \% ; 84.5 \%$ de nos indications). Dans les infertilités inexpliquées ( 6 de nos indications), le TG/C est le plus décevant (3.6\%).

34 IIU (30 couples) ont été réalisées à la place d'une FIV en raison de la mauvaise réponse à la stimulation : une seule grossesse a été obtenue ( $\mathrm{TG} / \mathrm{C}=2,9 \%)$.

Concernant la qualité du sperme, plus que les paramètres initiaux du spermogramme, 2 facteurs paraissent importants :

a) le nombre de spermatozoïdes mobiles progressifs (SMP) inséminés : le TG/C diminue de façon nette lorsque moins de 300000 SMP sont inséminés $(3.9 \%$ vs $13 \%$ si $>300000)$, alors qu'au delà de 300000 un nombre croissant de SMP inséminés n'augmente pas les chances de survenue d'une grossesse ;

b) la survie des spermatozoïdes à $24 \mathrm{H}$ : le TG/C est de $12.5 \%$ lorsque plus de $50 \%$ des spermatozoïdes sont mobiles après $24 \mathrm{H}$ vs $7.3 \%$ lorsque moins de $50 \%$ sont mobiles après $24 \mathrm{H}$ (et $0 \%$ lorsque tous les spermatozoïdes sont immobiles).

Le devenir des couples n'ayant pas obtenu de grossesse après IAC sera détaillé (passage en FIV, adoption, abandon du traitement, etc.).

\section{En conclusion}

Avant de proposer une IIU-AC, notre étude montre qu'il faudra prendre en compte notamment : l'âge de femme, la durée d'infertilité, le 
nombre de spermatozoïdes progressifs obtenus après CGP ainsi que leur taux de survie à $24 \mathrm{H}$ plutôt que les paramètres initiaux du spermogramme. On limitera volontairement le nombre d'IAC à 4 par couple. La stimulation de l'ovulation et son monitorage sont importants. Une stimulation peu contraignante par anti-E2 donne de bons résultats, tout en limitant les complications, sauf dans les dysovulations où l'HMG permet d'obtenir un meilleur taux de grossesse.

$\mathrm{Au}$ total, l'IIU-AC a sa place parmi les méthodes de traitement de l'infertilité, notamment d'origine masculine. Elle peut rester simple tout en donnant aux couples des chances satisfaisantes de succès à condition de bien poser ses indications.

$\bullet$

\section{APPORT STRATEGIQUE DU BILAN COMPLEMENTAIRE SPERMIOLOGIQUE APRES ECHEC DE FECONDATION IN VITRO}

M. Daniel, O. Paulmyer-Lacrorx, M. Mollar, A. Noizet, A. Guerin, M. GamerRe, J-M Grillo

Hôpital de la Conception-Laboratoire de Biologie de la Reproduction 147 Bd Baille-13005 Marseille

\section{Introduction}

L'étiologie des échecs de fécondation in vitro (FIV) est souvent difficile à déterminer. Il est donc important d'évaluer la qualité des gamètes de chacun des partenaires avant d'envisager une nouvelle tentative. Le spermogramme de routine ne peut expliquer à lui seul le défaut de fécondance. Le bilan complémentaire a donc pour but, d'apporter des renseignements supplémentaires sur la qualité spermatique qui permettent d'orienter le couple vers une Assistance Médicale à la Procréation (AMP) mieux adaptée.

Nous présentons ici les résultats de 23 bilans spermiologiques complémentaires réalisés après un ou plusieurs échecs de fécondation in vitro.

Nous avons essayé d'évaluer l'intérêt de ce bilan en analysant les choix thérapeutiques et les résultats de la nouvelle tentative d'AMP proposée aux couples.

\section{Matériel et Méthodes}

L'étude a été réalisée à partir de 23 patients ayant subi soit des échecs complets ou obtenu de faibles taux de clivage $(<20 \%)$ lors d'une tentative de FIV (indications : 18 masculines et 5 mixtes) Le bilan complémentaire spermiologique réalisé comprend les examens suivants :

- un spermogramme. La qualité du sperme est évaluée selon les recommandations de l'OMS.

- un test au Percoll avec appréciation du nombre de spermatozoïdes (Spz) en traces directes par champ au grossissement $x 40$ (après centrifugation sur gradient de Percoll, le culot est repris avec $0.3 \mathrm{ml}$ de B2 de MENE$\mathrm{ZO}, 10 \mathrm{TD} / \mathrm{champ}$ correspondent à 2.106 $\mathrm{Spz} / \mathrm{ml}$ ).

- un spermocytogramme avant et après centrifugation sur gradient de Percoll (CGP) (la classification employée est celle de David).

- une étude morphologique de l'acrosome après sélection des spermatozoïdes sur gradient de Percoll. Le marquage est réalisé avec la lectine PSA marquée par la FITC.

- une évaluation de la maturité nucléaire par le bleu d'aniline des spermatozoïdes sélectionnés par le test au Percoll.

Après analyse des résultats du bilan complémentaire, une nouvelle stratégie thérapeutique est définie. Les 23 couples ont été orientés vers une nouvelle tentative d'AMP de la façon suivante : 7 FIV classiques, 8 FIV en micro-goutte (volume de fécondation de $40 \mathrm{ml}$ en immersion sous huile) avec traitement du sperme par Pentoxifylline, 8 micro-injections intra-cytoplasmiques (ICSI).

\section{Conclusions}

L'analyse des résultats globaux permet de définir trois populations de patients qui présentent des altérations spermiologiques d'intensité croissante. Cette constatation générale souligne l'importance du bilan complémentaire dans la stratégie thérapeutique après échecs de FIV.

Ainsi après échecs de FIV, l'association des résultats de deux examens complémentaires permet notamment de poser l'indication de FIV en micro-goutte avant d'envisager une éventuelle micro-injection intra-cytoplasmique. Ces résultats sont:

- le rendement du test au Percoll avec un nombre de spermatozoïdes en traces directes compris entre 5 et $20 \mathrm{TD} / \mathrm{chp}$.

- et la cytologie après Percoll normale ou présentant une amélioration supérieure à $25 \%$. 
L'apport stratégique de l'étude morphologique de l'acrosome et de l'évaluation de l'immaturité nucléaire es plus difficile à interpréter. L'amélioration des techniques d'exploration du statut acrosomique avec mesure de la réaction acrosomique induite semble nécessaire avant d'envisager une participation à la stratégie thérapeutique.

Les anomalies de maturité nucléaire permettent dans certains cas d'apporter tout au plus une explication l'échec de fécondation in vitro. La place de cet examen, en cas d'échecs de fécondation in vitro par micro injection intra-cytoplasmique semble intéressante à définir.

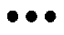

\section{INFLUENCE DE LA MORPHOLOGIE DES SPERMATOZOIDES SUR LA FECONDA- TION, LE CLIVAGE ET LA QUALITE EMBRYONNAIRE}

F. Eustache, H. Lucas, J. Auger, C. Poirot, JP. Wolf, P. JouAnNet

Service d'Histologie, Embryologie, Biologie de la Reproduction, Hôpital Cochin, 123 Bd du Port Royal, 75014 Paris, France

\section{Introduction}

L'objet de ce travail a été d'évaluer l'influence de la morphologie des spermatozoïdes inséminés au contact des ovocytes, sur les résultats de la fécondation in vitro (FIV).

\section{Matériel et méthodes}

L'étude a été faite à partir de 59 tentatives de FIV dont 44 avaient pour indication une stérilité tubaire associée ou non à une endomètriose, une dysovulation et une malformation utérine, et 15 avaient pour indication un échec d'insémination intrautérine, une endomètriose, une malformation utérine, une dysovulation ou une indication masculine. La FIV a été réalisée en microgoutte de $30 \mathrm{ml}$. Seules ont été retenues pour l'étude les FIV pour lesquelles au moins 4 ovocytes ont pu être inséminés.

Les femmes étaient âgées en moyenne de 34 ans (26 à 43 ans).

Les spermatozoïdes ont été préparés sur un gradient de Percoll à 2 concentrations (95\% $47.5 \%)$.

L'analyse morphologique a été faite à partir d'un frottis de spermatozoïdes sélectionnés, coloré selon la technique de Shorr. La morphologie de 100 spermatozoïdes a été évaluée d'après la classification de David et al. modifiée, incluant l'indice d'anomalies multiples (IAM).

5000 spermatozoïdes mobiles progressifs ont été inséminés par microgoutte, contenant un ovocyte.

\begin{tabular}{|c|c|c|c|c|c|}
\hline & & Taux de fécondation & Taux de clivage & Score embryonnaire & Effectifs \\
\hline \multirow{3}{*}{ IAM } & $1,1-1,3$ & 68,1 & 75 & $57,6 \mathrm{a}$ & 23 \\
\hline & $1,3-1,5$ & 55 & 62,8 & 42,5 & 20 \\
\hline & $>1,5$ & 56,4 & 58,4 & $37 \mathrm{a}$ & 16 \\
\hline Formes & $87-70$ & 66,6 & $76,4 \mathrm{~b}$ & 54,7 b & 23 \\
\hline typiques & $70-60$ & 61,4 & 70,5 & $56 \mathrm{a}$ & 15 \\
\hline$\%$ & $60-19$ & 53,3 & $52,4 \mathrm{~b}$ & $31,7 \mathrm{ab}$ & 21 \\
\hline Anomalies & $8-30$ & 66,9 & $79,7 \mathrm{~b}$ & 57,6 a a & 18 \\
\hline de la & $30-55$ & 63,9 & $68,7 \mathrm{a}$ & 49,1 a a & 24 \\
\hline tête $\%$ & $55-94$ & 49 & $48,9 \mathrm{~b}$ a & 32,3 a a & 17 \\
\hline Anomalies & $1-15$ & $74,7 \mathrm{~b}$ a & $79,4 \mathrm{a}$ & 59,4 & 18 \\
\hline de & $15-25$ & $52,9 \mathrm{~b}$ & 64,3 & 41,9 & 24 \\
\hline l'acrosome \% & $25-45$ & $56,3 \mathrm{a}$ & $55,4 \mathrm{a}$ & 40,6 & 17 \\
\hline Anomalies & $1-10$ & 61,5 & $74,9 \mathrm{a}$ & $57,3 \mathrm{a}$ & 18 \\
\hline de la & $10-25$ & 65,8 & 69,7 & $51,7 \mathrm{a}$ & 22 \\
\hline base $\%$ & $25-59$ & 53,5 & $54,3 \mathrm{a}$ & 31,3 a a & 19 \\
\hline
\end{tabular}

Test de Student : $a: p<0.05 b: p<0.01$ 
Les critères d'interprétation des résultats de la FIV étaient le taux de fécondation (rapport entre le nombre de zygotes et le nombre d'ovocytes en métaphase II), le taux de clivage (rapport entre le nombre d'embryons et le nombre d'ovocytes en métaphase II) et le score embryonnaire (rapport entre le nombre d'embryons de type A et B, et le nombre d'ovocytes en métaphase II). Les embryons de type $A$ et $B$ sont définis par un volume de fragments cellulaires occupant moins de $20 \%$ du volume total de l'embryon.

\section{Résultats}

Après préparation sur gradient de Percoll, les caractéristiques étaient les suivantes (moyenne +/- SEM) : la concentration était de 111.27 millions par $\mathrm{ml}(+/-10.88)$, la mobilité progressive était de $82 \%(+/-1.58)$, le pourcentage de forme typique était de $64(+/-1.89)$ et l'IAM était de $1.39(+/-0.02)$.

Une corrélation significative entre IAM et la morphologie d'une part, et les résultats de la fécondation d'autre part a pu être mise en évidence $(\mathrm{p}<0.05)$.

Les résultats sont présentés dans le tableau cidessus. Les valeurs sont exprimées en moyenne.

\section{Conclusion}

La diminution du pourcentage de formes typiques, l'augmentation de l'IAM et l'augmentation des anomalies de la tête sont donc responsables d'une diminution à la fois du taux de clivage et du score embryonnaire. D'autres études sont nécessaires pour préciser le rôle de l'altération morphologique des spermatozoïdes humains sur le développement embryonnaire.

\section{AUTOCONSERVATION DU SPERME CHEZ LES BLESSES MEDULLAIRES : EXPE- RIENCE DU CECOS DE BORDEAUX}

N'Guen Van Tam P.*, Mathieu C.**, MekLa H.*, MoRAND J.**, Blandin T **, MAYER G. ${ }^{* *}$

*Unité de soins des blessés vertébro-médullaires Centre de la Tour de Gassies 335323 Bruges Cedex ${ }^{*}$ CECOS Laboratoire de Biologie de la Reproduction et Génétique Biologique, Hôpital Pellegrin Place Amélie Raba Léon 33076 Bordeaux cedex.

\section{Introduction}

Les possibilités de reproduction des blessés médullaires sont compromises par l'atteinte des fonctions sexuelles et l'atteinte de la qualité du sperme dont la sévérité est variable. Nous avons proposé aux blessés médullaires une stimulation de l'éjaculation et une autoconservation du sperme en vue d'assistance médicale à la procréation pour pallier des échecs de stimulation et/ou une dégradation de la spermatogenèse.

\section{Matériel et Méthodes}

- Nombre de patients : 33 de janvier 93 à septembre 96

Age au moment du traumatisme :

$<20$ ans : 15 patients $>20$ ans : 18 patients

Niveau de la lésion : 20 cervicales, 13 dorsales.

Age au moment de l'autoconservation :

$<20$ ans: 3 patients $>20$ ans: 30 patients

Délai entre traumatisme et autosonservation : Extrêmes : 6 mois - 12 ans.

Patients sans antécédent urologique particulier (i,e,: injection urinaire chronique)

- Existence d'un projet parental : 11 cas.

- Nombre de cycles de stimulation de l'éjaculation : 85 cycles

Méthodes :

- Vibromassage : 71 cycles 26 patients

- Pharmacologique + vibromassage $: 8$ cycles 3 patients

-Electro-stimulation :6 cycles 4 patients

\section{Résultats}

- Absence d'éjaculation : 20 cycles

- Sperme incongelable : 7 cycles

- Qualité du sperme (29 patients 58 échantillons).

Volume moyen : 2,2 ml (extrêmes 0,1 - 6,4)

Numération $10 \% / \mathrm{ml}$ :

$15 \mathrm{~N}<5: 3$ cas $5 \mathrm{~S} \mathrm{~N}$ c $20: 8$ cas

20 c $\mathrm{N}<60$ : 15 cas N 2 60: 32 cas

Formes typiques

$\geq 50 \%: 15$ cas $\quad<50 \%: 35$ cas

Mobilité avant congélation \%

$0: 3$ cas $\quad M<10: 12$ cas $10 \leq M<20: 16$ cas

$20 \leq \mathrm{M}<40: 22$ cas

$\mathrm{M} \geq 40: 5 \mathrm{cas}$

Mobilité après décongélation \% 


$\begin{array}{lll}0: 13 \text { cas } & <1: 11 \text { cas } & 1 \leq M \leq 5: 14 \text { cas } \\ 5 \leq \mathrm{M} & <10: 11 \text { cas } & 10 \leq M<20: 9 \text { cas }\end{array}$

\section{Discussion}

Les échecs de stimulation sont en rapport avec le niveau lésionnel (D12 flasque). L'atteinte majeure du spermogramme porte sur la mobilité avec une chute dramatique après congélation. Il paraît donc logique d'utiliser le sperme frais en priorité pour l'AMP en ayant le sperme de congélation comme moyen de secours. La qualité du sperme congelé chez nos patients n'autorise qu'une AMP type fécondation in vitro avec micro-injection (ICSI).

Notre série est encore trop réduite pour répondre à 2 questions :

- la qualité du sperme est elle influencée par l'âge au moment du traumatisme médullaire?

- la qualité du sperme dépend-elle du délai traumatisme-autoconservation?

\section{INFECTION DU SPERME ET AMP}

\section{LE TESTICULE, ORGANE CIBLE DU CYTOMEGALOVIRUS MURIN : IMPACT SUR LA DESCENDANCE}

\author{
I. Ceruttit ${ }^{*}$, G. Blanc-Layrac** ${ }^{*}$, A.M. Cour- \\ TOT**, J. TESTART** \\ * S.E.A.T., I.F.C. I, C.N.R.S., Institut de \\ Recherche sur le Cancer, 7, rue Guy Moquet \\ 94800 Villejuif. \\ ** INSERM, Unité 355, 32, rue des Camets, \\ 92140 Clamart
}

Dans le cadre d'une étude sur le transport d'informations, nous avons tout d'abord vérifié par les techniques autoradiographiques, la fixation d'ADN plasmidique sur les spermatozoïdes humains et murins (Courtot et al, SALF, Deauville,1994). Les résultats obtenus, en faveur d'une fixation de l'ADN sur/dans les spermatozoïdes, nous ont amenés à continuer nos recherches en vérifiant le comportement des gamètes mâles au cours d'une infection virale.
Le cytomégalovirus (CMV) utilisé dans cette étude, est un modèle de choix car il répond à différents critères :

- Spécifique d'espèce, il induit chez l'homme une maladie comparable à celle retrouvée dans un modèle expérimental, (souris - cytomégalovirus murin) avec entre autre, des anomalies foeto-maternelles.

- Aucune relation n'a pu être mise en évidence, à ce jour, entre l'infection paternelle et sa descendance.

- De plus, par son infectiosité pour le sperme, le CMV est, chez l'homme, un cofacteur aggravant de l'évolution de l'infection par HIV.

Notre étude est réalisée chez le souriceau, le mâle adulte et sa descendance, en comparant deux souches de cytomégalovirus murin (MCMV), l'une purifiée sur système cellulaire, l'autre provenant d'un broyat de glandes salivaires issu d'un animal infecté.

Des arguments de biologie moléculaire (PCR) et ultrastructuraux (microscopie électronique à transmission) sont en faveur d'une présence d'ADN viral ou de virions dans les testicules des souriceaux infectés par voie générale (intrapéritonéale). Les mêmes résultats sont obtenus chez les mâles adultes infectés localement (voie intratesticulaire). Cette infection, souvent létale chez le souriceau, s'accompagne d'une production d'interféron sérique. Par contre, en ce qui concerne le mâle adulte, on ne décèle aucun signe clinique apparent ni production d'interféron.

L'impact de cette présence virale, dans les testicules de ces animaux, est analysé, sur la descendance, et discuté principalement au cours des injections de gamètes mâles sous la zone pellucide ou dans l'ooplasme.

Nous remercions particulièrement Monsieur le Professeur M. AUROUX pour ses conseils judicieux, Ariette LOEUILLET, René DUCHATEAU, Jean Paul MOUS$S U$ et Patrice MEDINA pour leur excellente aide technique. La microscopie électronique et les photographies correspondantes ont été réalisées au C.I.M.E. (C.N.R.S. Jussieu). 


\section{CYTOMEGALOVIRUS ET PROCREATION MEDICALEMENT ASSISTEE}

R. LeVY*, B. KePPI**, F. NaJIOUllah**, S. BosSHARD $^{* *}$, D. ThOUVENOT ${ }^{* *}$, B. LINA**, M.

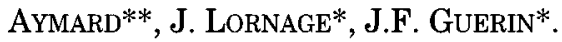

* Laboratoire de Biologie de la Reproduction et du Développement. Hôpital Edouard Herriot, Place d'Arsonval, 69437 Lyon cedex 03

** Laboratoire de Virologie, Faculté de Médecine Lyon Grange Blanche, Domaine Rockefeller, 69373 Lyon Cedex 08

\section{Introduction - Buts}

Le cytomégalovirus (CMV) est un virus ubiquitaire et endémique dont la prévalence varie fortement en fonction de l'origine géographique, l'âge et la classe socio - économique. L'infection à cytomégalovirus survenant chez la femme enceinte est la première cause d'infection virale congénitale affectant 0,2 à $2,29 \%$ des nouveaux nés vivants, soit 40000 naissances par an aux Etats Unis et 1500 naissances en France.

La présence du CMV dans le sperme et sa détection restent encore débattues.

Le développement de nouvelles techniques d'aide médicale à la procréation (AMP) comme la micro - injection d'un spermatozoïde à l'intérieur d'un ovocyte décoronisé a fait reconsidérer cet agent comme source potentielle d'infection maternelle et materno - fœtale.

\section{Matériel et Méthodes}

Les séroprévalences IgM, IgG anti - CMV par technique ELISA de 100 couples suivis en fécondation in vitro dans notre unité ont été effectuées. Les caractéristiques du spermogramme et les résultats après FIV ont été analysés.

Détection en culture cellulaire du virus et mise au point d'une technique rapide de détection du génome viral du CMV par amplification génique et hybridation en sonde froide sur le sperme et ses différentes fractions après traitement.

\section{Résultats}

$39 \%$ des spermes étudiés correspondant à des sujets présentant une sérologie CMV positive (IgG) ont présenté un effet cytopathogène spécifique du cytomégalovirus après 3 semaines en culture et une détection positive de1'ADN viral après PCR et hybridation.

\section{Discussion}

Le cytomégalovirus a pu être mis en évidence dans le sperme d'une population d'hommes séropositifs pour le CMV suivis en fécondation in vitro et son $\mathrm{ADN}$ a pu être détecté par une technique rapide (48 heures) et sensible: la PCR. Même si la prévalence du CMV dans le sperme d'hommes séropositifs pour ce virus est peu élevée, il doit être tenu compte de cette donnée dans la conduite à tenir avant toute AMP.

\section{PREVALENCE DE L'INFECTION A CHLA- MYDIA TRACHOMATIS ETUDIEE PAR 3 TECHNIQUES DIAGNOSTIQUES DANS LE TRACTUS GENITAL DE 100 HOMMES DE COUPLE INFERTILE}
A. KerJe*, J. Auger*, G. PAUL ${ }^{* *}$, P. NÉvot**, P. JOUANNET*, M.V. ASSOUS**
* Laboratoire de Biologie de la Reproduction, Hôpital Cochin,123 Bd du Port Royal, 75014 Paris
** Laboratoire de Microbiologie, Hôpital Cochin; Laboratoire de Recherche en Microbiolo- gie, Faculté de Médecine Cochin, 24 rue du fau-
bourg Saint-Jacques. 75674 Paris Cedex 14

L'infection à Chlamydia trachomatis du tractus génital de l'homme, malgré l'efficacité des traitements antibiotiques, continue à poser des problèmes de santé publique. Ces problèmes sont liés au caractère très fréquemment asymptomatique de l'infection urogénitale et aux difficultés de détection de Chlamydia trachomatis par les méthodes microbiologiques classiques. L'objectif de ce travail était d'évaluer la prévalence de l'infection urogénitale asymptomatique à Chlamydia trachomatis chez des hommes de couple infertile, par biologie moléculaire. Trois méthodes de diagnostic direct ont été utilisées :

- l'immunofluorescence directe (Syva Microtrak,),

- la Ligase Chain Reaction (LCR) Chlamydia trachomatis selon la technique Abbott (LCX Kit,),

- la Polymerase chain reaction (PCR) avec amorces plasmidiques, révélée en dot blot par sonde froide chémiluminescente, mise au point au laboratoire de Microbiologie et préalablement validée sur sperme et urine. 
De Mai à Août 1996, 100 patients consécutifs, adressés pour spermoculture au laboratoire de Biologie de la Reproduction, ont été inclus. La spermoculture était faite dans le cadre d'un bilan diagnostique pour infertilité masculine $(\mathrm{n}=$ 39) ou avant fécondation in vitro $(n=61$ dont 22 pour stérilité tubaire). L'interrogatoire des patients a permis de déterminer que 9 avaient des antécédents d'infections à Chlamydia trachomatis, 4 avaient pris des antibiotiques à large spectre dans les 3 semaines précédant l'examen et 6 avaient un antécédent de prostatite chronique. Après recueil du premier jet d'urine, le sperme a été prélevé par masturbation, en tube stérile, au laboratoire. Chaque échantillon de sperme a été analysé par les 3 méthodes diagnostiques et chaque échantillon d'urine par les 2 méthodes de biologie moléculaire. La recherche deChlamydia trachomatis a été négative pour tous les échantillons par les 3 techniques utilisées.

Ces résultats sont en accord avec les données de la littérature, si l'on considère le type de technique diagnostique mises en œuvre et la variabilité des populations étudiées par les différentes études. Le faible taux de positivité de détection et la faible prévalence de Chlamydia trachomatis renforcent l'intérêt des techniques de biologie moléculaire, pour le diagnostic microbiologique de l'infection génitale masculine et pour un dépistage plus efficace des spermes infectés avant toute AMP. Néanmoins, ce travail doit être poursuivi en incluant d'autres hommes infertiles, afin d'affiner la comparaison entre les 3 méthodes utilisées pour le diagnostic de Chlamydia trachomatis.

\section{CRYOCONSERVATION}

\section{ROLE DU LIQUIDE SEMINAL DANS LA CRYOPRESERVATION DES SPERMATOZOIDES HUMAINS}

\author{
V. Chevalier, C. Nouallles, B. Sion, O. Bou- \\ CHER, G. GRIZARD
}

Service de Biologie du Développement et de la Reproduction, CECOS Hôtel-Dieu, Boulevard Léon Malfreyt 63000 Clermont-Ferrand

\section{Objectifs}

Le but du travail a été d'apprécier le rôle du liquide séminal (LS) sur la tolérance des spermatozoïdes humains à la cryopréservation. Pour cela nous avons réalisé des congélations avec et sans liquide séminal et en présence ou non d'une source lipidique (liposomes de phosphatidylcholine distéaroyl, PC18 et de cholestérol CHOL, $\mathrm{PC} 18 / \mathrm{CHOL}$ ) ou d'une source protéique (sérum albumine bovine, BSA).

\section{Matériel et Méthodes}

Les spermes retenus pour cette étude présentent les caractéristiques suivantes : volume de l'éjaculat $\geq 2 \mathrm{ml}$, vitalité $\geq 70 \%$, mobilité totale $\geq$ $50 \%$, nombre $\geq 50 \times 106 / \mathrm{ml}$, formes typiques $\geq$ $40 \%$, cellules rondes $\geq 5 \times 106 \mathrm{ml}$, polynucléaires $\geq$ $1 \times 106 / \mathrm{ml}$.

La composition des différents milieux utilisés est la suivante :

- Le milieu de congélation B : Glutamine $80 \mathrm{mM}$; Fructose $0,35 \%$ (P/V) ; Citrate de sodium $0.66 \%$ $(\mathrm{P} / \mathrm{V})$; Chlorure de sodium $0,18 \%$; Glycérol $14 \%$; Streptomycine $400 \mathrm{mg} / \mathrm{ml}, \mathrm{PH} 7,4$.

- Le milieu de substitution (T6) : Chlorure de sodium $0,55 \%(\mathrm{P} / \mathrm{V})$; Chlorure de potassium $0.035 \%(\mathrm{P} / \mathrm{V})$; Sulfate de magnésium $0,01 \%$ $(\mathrm{P} / \mathrm{V})$; Phosphate de sodium monobasique $0,012 \%$ (P/V); Bicarbonate de sodium $0,21 \%$ (P/V) ; Lactate de sodium $0,24 \%(\mathrm{P} / \mathrm{V})$; Pyruvate de sodium $0,003 \%(\mathrm{P} / \mathrm{V})$; Glucose $0,1 \%(\mathrm{P} / \mathrm{V})$; Chlorure de calcium $0,026^{\circ} \%(\mathrm{P} / \mathrm{V})$; Pénicilline $0,06 \mathrm{mg} / \mathrm{ml}$; Streptomycine $0,05 \mathrm{mg} / \mathrm{ml}$; Rouge de phénol $0,001 \%(\mathrm{P} / \mathrm{V})$.

Les spermes sont centrifugés $(500 \mathrm{~g}, 10 \mathrm{~min})$ et les spermatozoïdes resuspendus doucement dans les différents milieux :

Groupe I : LS +B (V/V);

Groupe II : B ;

Groupe III : B + liposomes PC18/CHOL $(50 \mu \mathrm{M})$; Groupe IV : T6 +B (V/V) ;

Groupe V: T6 + B (V/V) + liposomes PC18/ CHOL $(50 \mu \mathrm{M})$;

Groupe VI : T6 + B (V/V) + BSA (1,5\%).

Les mélanges sont répartis dans des paillettes de $0,25 \mathrm{ml}$ et congelés à l'aide d'un minicool (LC40 ; Air Liquide France). Les paillettes sont refroidies de la température ambiante à $-4^{\circ} \mathrm{C}$ à 
une vitesse de $5^{\circ} \mathrm{C}, / \mathrm{min}$, de $-4^{\circ} \mathrm{C}$ à $-30^{\circ} \mathrm{C}$ $\left(10^{\circ} \mathrm{C} / \mathrm{min}\right)$, de $-30^{\circ} \mathrm{C}$ à $-140^{\circ} \mathrm{C}\left(20^{\circ} \mathrm{C} / \mathrm{min}\right)$ pour finalement être plongées dans l'azote liquide à $196^{\circ} \mathrm{C}$. Les paillettes sont décongelées rapidement à l'étuve $\left(37^{\circ} \mathrm{C}, 3 \mathrm{~min}\right)$.

\section{Résultats}

La suppression du liquide séminal entraîne une chute significative de la mobilité $(48 \%)$ et de la vitalité $(31 \%)$ que le milieu soit supplémenté ou non avec des liposomes (II, III vs I).

Le remplacement du LS par le T6 n'entraîne pas de modification significative de la vitalité et de l'activité cinétique des spermatozoïdes avant et après congélation (IV vs I), en effet, la perte de mobilité (19\%) lors du processus de congélation/décongélation avec le T6 est comparable à celle obtenue lors de la congélation avec le LS $(21 \%)$, il en est .de même pour la vitalité ( $20 \%$ vs $15 \%)$.

L'addition de liposomes PC18/CHOL ou de BSA dans le milieu T6 n'entraîne aucun effet bénéfique ou délétère sur la mobilité et la vitalité des spermatozoïdes congelés/décongelés (V, VI vs I, et IV)

\section{Conclusions}

Dans nos conditions expérimentales :

- le liquide séminal peut-être substitué par un milieu synthétique.

- La présence de lipides apportés sous forme de liposomes de PC18/CHOL dans les milieux cryoprotecteurs n'entraîne aucun effet délétère ou bénéfique sur la survie et sur les caractéristiques cinétiques des spermatozoïdes.

- De même, la BSA ne semble pas modifier ces paramètres.

ESPECES ET SOUS-ESPECES PHOSPHOLIPIDIQUES DU SPERMATOZOIDE HUMAIN : RELATION AVEC LA MOBILITE ET LA RESISTANCE A LA CONGELATION

\author{
S. ZEKRI*, P. THEROND**, J. AUGER* ${ }^{*}$ P. JOUAN- \\ NET \\ * Laboratoire de Biologie de la Reproduction. \\ Hôpital Cochin. \\ **Laboratoire de Biochimie A. Hôpital Bicêtre
}

\section{Introduction}

La congélation des spermatozoïdes dans les vapeurs d'azote est à l'origine d'altérations cellulaires qui diminuent le pouvoir fécondant des spermatozoïdes après décongélation. Parmi ces altérations, on note des modifications biochimiques dans la composition et l'organisation des lipides membranaires en rapport, notamment, avec une peroxydation.

\section{Objectif}

Dans ce travail, nous avons poursuivi les objectifs suivants :

- Décrire la composition lipidique des membranes du spermatozoïde humain, avant congélation et après dégel, par chromatographie.

- Rechercher s'il existe une relation entre cette composition et divers paramètres fonctionnels des spermatozoïdes.

- Etudier la relation entre les peroxydes lipidiques éventuellement produits après congélation/dégel et la mobilité et la vitalité des spermatozoïdes.

\section{Matériel et Méthodes}

Les échantillons de sperme utilisés provenaient de donneurs volontaires sains $(n=9)$. Les paramètres spermatiques ont été mesurés selon les recommandations de l'OMS. La congélation a été réalisée selon la méthode utilisée au CECOS. Les lipides ont été extraits par centrifugation dans un mélange chloroforme-méthanol et séparés par CLHP.

\section{Résultats}

Les résultats montrent :

* la prédominance des phospholipides portant la paire d'acides gras 16:0/22:6 (54\%), ainsi que des plasmalogènes (34\%).

* une grande variabilité intra et inter-individuelle dans la répartition en sous-espèces lipidiques.

* une corrélation entre mobilité initiale et quantité de lipides en 16:0/22:6.

* une baisse, après dégel, de la plupart des sousespèces phospholipidiques $(17,3 \%$ pour les phospholipides et $17,7 \%$ pour le cholestérol) sans que le profil lipidique soit modifié par le milieu cryoprotecteur. 
* Dans 6 cas sur 8, une production d'hydroperoxydes $(\mathrm{LOOH})$ a été notée après dégel (303 \pm 269 pmoles/108 spermatozoïdes). La quantité de LOOH produite est corrélée négativement au pourcentage initial de spermatozoïdes mobiles et positivement à la consommation des phospholipides en 16:0122:6.

* cette production de $\mathrm{LOOH}$ est identique à celle produite expérimentalement in vitro en induisant la peroxydation par l'oxygène singulet.

\section{Conclusion}

Ce travail suggère que la richesse initiale des spermatozoïdes en plasmalogènes est un facteur déterminant pour la protection des autres lipides contre l'attaque des radicaux libres de l'oxygène, diminuant ainsi la production de peroxydes lipidiques aux effets nocifs sur les spermatozoïdes.

\section{AZOOSPERMIE ET ICSI}

\section{BILAN DE L'AZOOSPERMIE ET DE LA QUALITE DES GAMETES AVANT ICSI}

\section{INTERET DES MARQUEURS BIOCHIMIQUES SEMINAUX POUR LA CLASSIFICATION DES AZOOSPERMIES : APPORT DE L'ANALYSE PAR COURBE ROC}

\author{
A. Kerjean*, J. Auger*, B. Cherruau**, G. Sar- \\ FATI $^{* *}$, D. NGUYEN-DAI**, P. JouANNET* \\ *Laboratoire de Biologie de la Reproduction (P. \\ Jouannet), Hôpital Cochin, 123 Bd du Port \\ Royal, 75014 Paris, France \\ **Laboratoire de Biochimie A (O.G. Ekindjian), \\ Hôpital Cochin, 27 rue du Fg Saint Jacques, \\ 75679 Paris, France
}

\section{Résumé}

Les valeurs des normales de la biochimie séminale varient d'un laboratoire à l'autre, non seulement en raison des différentes techniques employées et des références cliniques, mais également en raison de la méthodologie statistique à laquelle on a recours pour les définir. L'objet de ce travail a été de déterminer si une classification des azoospermies pouvait être faite sur les seules données de la biochimie séminale, par analyse de type courbe ROC (Receiver Operating Characteristic curve). Une classification étiologique des azoospermies a initialement été établie en fonction du diagnostic clinique, de l'anamnèse, de la valeur de la FSH, complétés parfois d'une exploration échographique, chirugicale voire anatomopathologique après biopsie. A partir de cette classification, pour chaque étiologie d'azoospermie, ont été définis des groupes à diagnostic certain (tous critères réunis), probable (1 critère manquant) ou douteux ( 2 critères manquants). La répartition au sein de chaque groupe était de 46 azoospermies excrétoires dont 28 certaines, 16 probables, 2 douteuses ; 34 azoospermies sécrétoires dont 22 certaines, 11 probables, 1 
Tableau 1 : valeur seuil des marqueurs biochimiques selon le type d'azoospermie. Les valeurs indiquées par la même lettre sont signifícativement différentes $(p<0,00001)$.

\begin{tabular}{lccccc}
\hline & \multicolumn{2}{c}{ Azoospermies sécrétoires } & \multicolumn{2}{c}{ Azoospermies excrétoires } \\
\cline { 2 - 5 } & & Toutes & Certaines & Toutes & Certaines \\
\hline Alpha 1-4 glucosidase & mU/éjaculat & $\geq 37^{\mathrm{a}}$ & $\geq 58^{\mathrm{b}}$ & $\leq 22^{\mathrm{a}}$ & $\leq 12^{\mathrm{b}}$ \\
Fructose & $\mu^{\mathrm{b}}$ & $\geq 50^{\mathrm{c}}$ & $\geq 55^{\mathrm{d}}$ & $\leq 36^{\mathrm{c}}$ & $\leq 42 \mathrm{~d}$ \\
L-carnitine & nmole/éjaculat & $\geq 650^{\mathrm{e}}$ & $\geq 800^{\mathrm{f}}$ & $\leq 525^{\mathrm{c}}$ & $\leq 460^{\mathrm{f}}$ \\
\hline
\end{tabular}

douteuse et 9 azoospermies ont été classées mixtes. Les azoospermies excrétoires certaines se répartissaient en 11 agénésies vésiculo-déférentielles bilatérales, 8 vasectomies, 5 obstructions épididymaires bilatérales et 4 obstructions bilatérales en amont de l'épididyme. Les marqueurs biochimiques séminaux étudiés étaient le fructose, le citrate, le zinc, la phosphatase acide, la L-carnitine et l'alpha 1-4 glucosidase. Deux types d'analyse ont été réalisées :

- une analyse statistique descriptive et comparaison des différents groupes étudiés par test non paramétrique,

- une analyse par courbe ROC avec détermination de seuil décisionnel visuel pour les marqueurs biochimiques.

Les valeurs seuil des marqueurs de la biochimie séminale déterminées pour les différents types d'azoospermies sont présentées dans le tableau 1.

Parmi les azoospermies excrétoires certaines, le meilleur marqueur pour différencier une obstruction épididymaire d'une agénésie est le fructose puis, la L-carnitine. Enfin, la L-carnitine est intéressante pour distinguer les agénésies et les vasectomies. En conclusion, nous avons trouvé que le meilleur critère décisionnel pour différencier une azoospermie excrétoire d'un azoospermie sécrétoire est l'alpha 1-4 glucosidase, puis le fructose et la L-carnitine qui ont sensiblement la même valeur informative. Les marqueurs biochimiques sont normaux dans les cas d'obstruction bilatérale en amont de l'épididyme. Les marqueurs prostatiques n'ont pas d'intérêt dans la classification biochimique choisie des différentes azoospermies.
VALEUR PREDICTIVE DE LA MESURE DU VOLUME TESTICULAIRE ET DE LA CONCENTRATION PLASMATIQUE DE FSH, POUR LA PRESENCE OU L'ABSENCE DE SPERMATOZOÏDES DANS LES BIOPSIES TESTICULAIRES

\author{
H. Lejeune, F. Cardona, N. Berger-DutrieuX \\ $\mathrm{N}^{*}$, M. Devonec ${ }^{* *}$, M. Pugeat \\ Clinique Endocrinologique, Laboratoire d'Anato- \\ mopathologie, Service d'Urologie, Hôpital de \\ l'Antiquaille Lyon, France (INSERM $n^{\circ} 493010$ )
}

Afin d'évaluer la valeur prédictive de la présence de spermatozoïdes dans la biopsie testiculaire des marqueurs cliniques et biologiques classiquement utilisés pour le diagnostic des troubles de la spermatogenèse, nous avons mené une étude rétrospective portant sur 40 patients présentant une infertilité pour laquelle une indication d'exploration chirurgicale avec réalisation de biopsies testiculaires a été retenue.

\section{Matériel et méthodes}

Les indications opératoires correspondaient à : un tableau d'infertilité excrétoire (11 patients), un tableau associant une suspicion de pathologie excrétoire et/ou d'altération de la spermatogenèse (17 patients), une cure de varicocèle ( 7 patients), une cure de cryptorchidie persistant à l'âge adulte (3 patients), 2 tuméfactions scrotales (1 tumeur et une épididymite chronique avec pachyvaginalite). L'étude a porté sur les relations entre les données anatomopathologiques et le volume testiculaire (Vol T) mesuré avec un orchidomètre de Prader, et la concentration plasmatique de FSH mesurée par dosage radioimmunologique.

\section{Résultats}

Il existe une corrélation significative entre le Vol $\mathrm{T}$ et le score $\mathrm{T}$ décrivant les lésions du tube 
séminifêre dans la classification de Valette ( $\mathrm{r}=$ 0,$463 ; \mathrm{p}<0,0001$ ) et entre le Vol T et le nombre de formes allongées (spermatozoides et/ou spermatides allongées) dans 100 tubes séminifères ( $p$ de Spearman $=+0,412 ; p=0,0013$ ). Le Vol T est significativement différent dans les 5 classes définies par la description anatomopathologique: "bonne valeur fonctionnelle", "oligospermatogenèse modérée", "oligospermatogenèse sévère", "arrêt de maturation", "aplasie germinale" (anova ; $\mathrm{p}=0,0007$ ). Le Vol $\mathrm{T}$ est significativement plus bas en cas d'absence de spermatides allongées (test $\mathrm{U}$ de Mann Whitney ; $\mathrm{p}=0,0138$ ).

La FSH plasmatique est corrélée avec la somme des scores $\mathrm{T}$ de Valette des 2 testicules $(r=+0,492 ; p=0,0031)$, avec la somme des nombres de formes allongées pour les deux testicules ( $p$ de Spearman=-0,532; $p=0,009$ ). La FSH est significativement supérieure lorsque l'un au moins des testicules présente des lésions sévères de la spermatogenèse (anova; $p=0,003$ ).

Toutefois, les courbes ROC (Receiver Operating Characteristic) qui représentent les variations de la sensibilité de détection en fonction de $1 a$ spécificité de détection selon les valeurs seuils choisies, montrent que le Vol T et la FSH plasmatique ne permettent de prédire qu'imparfaitement la présence ou l'absence de formes allongées dans les biopsies testiculaires. Dans l'échantillon de patients étudiés, on trouve des biopsies avec absence de formes allongées pour des volumes testiculaires allant jusqu'à $20 \mathrm{ml}$ et des FSH plasmatiques à partir de 9,5 UI/ et des biopsies testiculaires avec présence de formes allongées pour des volumes testiculaires à partir de $11 \mathrm{ml}$ et des FSH plasmatiques allant jusqu'à 29,5 UI/l. Les meilleurs compromis (valeur maximale du rapport valeur prédictive positive / 1-valeur prédictive négative) consistent à choisir un seuil de volume testiculaire $<11 \mathrm{ml}$ (risque relatif d'absence de formes allongées $=4$ ) et un seuil de concentration plasmatique de FSH $>12$ $\mathrm{UI} / 1$ (risque relatif d'absence de formes allongées= 4,3).

\section{Conclusion}

Cette étude permet de préciser les valeurs prédictives positives et négatives du volume testiculaire et de la concentration plasmatique de FSH en ce qui concerne la présence de spermatozoïdes testiculaires qui peuvent être utilisés dans des protocoles de microinjection dans des cas d'azoospermie. On constate qu'à l'échelon individuel, et dans notre échantillon, seules des valeurs extrêmes permettent de prédire de manière fiable la présence (Vol $\mathrm{T}>20 \mathrm{ml}$; FSH $<9,5 \mathrm{UI} /$ ) ou l'absence (Vol T $<11 \mathrm{ml}$; FSH $>$ 29,5 UI/1) de formes allongées dans les biopsies testiculaires.

\section{DETECTION DE MICRODELETIONS DU CHROMOSOME Y CHEZ DES PATIENTS AZOOSPERMIQUES}

R. Rousseaux-Prevost*, J.M. Rigot, *,**, F. CoLLIER $^{* * *}$, E. HERMAND ${ }^{\circ}$, B. Delobeli, ${ }^{*},{ }^{\circ}$, P. LeSuR $^{\circ \circ}$, M.F. CroquetTes ${ }^{\circ \circ}$, A. GaUthieR***, J. Rousseati*

$$
\begin{gathered}
* \text { EA 1719, IRCL, Lille } \\
\text { ** Service d'Urologie, CHRU, Lille } \\
* * * \text { Service de Gynécologie Sociale, CHRU, Lille } \\
{ }^{\circ} \text { Laboratoire de Cytologie et de Biologie de la } \\
\text { Reproduction, CHRU, Lille } \\
{ }^{\circ} \text { Laboratoire de Cytogénétique, Hôpital Saint- } \\
\text { Antoine, Lille } \\
{ }^{\circ \circ} \text { Laboratoire d'Analyses Médicales, Lille }
\end{gathered}
$$

\section{Introduction}

Des données récentes suggèrent qu'il existe une fréquence relativement importante de microdélétions du chromosome $\mathrm{Y}$ dans la région $\mathrm{AZF}$ chez des hommes présentant une azoospermie ou une oligospermie sévère. Un premier groupe de gènes candidats (YRRM) a été proposé en 1993 par le groupe de Chandley comme faisant partie de la région AZF. En 1995, un autre gène, dénommé DAZ, a été identifié dans la même région. Nous présentons ici les résultats de la recherche des gènes YRRM et DAZ chez 21 patients azoospermiques dont la spermatogenèse a été évaluée par biopsie testiculaire.

\section{Matériels et Méthodes}

La présence des gènes YRRM1 et DAZ a été recherchée par PCR de l'ADN génomique provenant de 21 patients azoospermiques à caryotype normal. Chez les patients négatifs pour le gène DAZ, la recherche de microdélétions dans les intervalles 5 et 6 du chromosome $\mathrm{Y}$ a été effectuée par STS-PCR. L'analyse histologique de la spermatogenèse a été réalisée sur biopsie testiculaire chez 13 patients. 


\section{Résultats}

Le gène YRRM1 a été retrouvé chez tous les patients étudiés. La recherche du gène DAZ par PCR intra-génique s'est révélée négative pour 2 patients $(9,5 \%)$. L'absence du gène $\mathrm{DAZ}$ est en relation avec une microdélétion de la partie distale de l'intervalle $6 \mathrm{du}$ chromosome Y. Chez les 2 patients présentant une microdélétion la spermatogénèse est profondément altérée mais la présence de quelques spermatides est observée.

\section{Discussion}

Notre étude réalisée chez des hommes azoospermiques montre une fréquence des microdélétions de la partie distale de l'intervalle $6 \mathrm{du}$ chromosome $Y$ comparable aux travaux précédemment publiés. La microdélétion s'accompagne d'une absence $d u$ gène $D A Z$ mais d'une présence $d u$ gène YRRM1 en accord avec les données récentes montrant la présence de copies multiples de ce gène sur le chromosome Y. La présence d'un faible nombre de spermatides chez les patients porteurs de microdélétion confirme que la recherche des microdélétions du chromosome $\mathrm{Y}$ devrait faire partie du bilan préalable à l'ICSI afin d'informer le couple du risque de procréer un garçon infertile.

\section{$\bullet \bullet$}

\section{RECHERCHE DE MICRO-DELETIONS DU CHROMOSOME Y CHEZ DES PATIENTS AZOOSPERMES}

L. Bujan, H.L. Plaisancie, G. Bourrouillou, A. Mansat, F. Pontonnier, R. Mieusset

Centre de Stérilité Masculine et CECOS MidiPyrénées CHU La Grave 31052 Toulouse Cedex

\section{Introduction}

La mise en évidence de macro délétions du bras long du chromosome $\mathrm{Y}$ chez des patients azoospermes par Tiepolo et al dès 1976 a fait évoquer l'existence d'une zone impliquée dans l'azoospermie : AZF. Récemment la mise au point de marqueurs génomiques du chromosome $\mathrm{Y}$ a permis à plusieurs groupes de rapporter des micro-délétions de l'Y chez des patients azoospermes ou plus récemment oligospermes. Ma et al, ont proposé YRRM comme gène candidat pour l'AZF et Reijo et al, clonent un gène également candidat : DAZ. Notre étude a pour objectif la recherche de micro-délétions dans la zone AZF y compris la zone du gène DAZ.

\section{Matériel et Méthodes}

Patients : 33 hommes azoospermes sont répartis en 3 groupes en fonction des résultats des examens cliniques et paracliniques : azoospermies sécrétoires $(n=14)$, azoospermies excrétoires $(n=16)$, azoospermies non identifiées $(n=3)$. Le caryotype a été réalisé chez 21 patients et l'analyse moléculaire chez tous les patients. Après extraction de l'ADN au phénol chloroforme l'amplification en chaîne par la polymérase (PCR) est réalisée avec les amorces correspondant à des marqueurs génomiques intéressant la zone $\mathrm{AZF}$ et $\mathrm{DAZ}$. Les résultats sont considérés comme négatifs lorsqu'au moins trois PCR sont négatives, un témoin positif, un négatif et un blanc étant inclus dans chaque série.

\section{Résultats}

Patients azoospermes secrétoires : le tableau 1 rapporte les caractéristiques cliniques et les antécédents. Sur 10 caryotypes effectués 5 sont anormaux : 2 présentant une anomalie numérique des gonosomes, 3 une anomalie des autosomes. L'étude des marqueurs génomiques montre des résultats négatifs chez deux patients dont un n'a pas de chromosome Y (homme XX).

Patients azoospermes excrétoires : le tableau 2 rapporte les caractéristiques cliniques et les antécédents de ces patients chez qui aucune délétion n'a été mise en évidence dans les régions étudiées.

\section{Discussion}

La fréquence des anomalies du caryotype chez les patients ayant une azoospermie sécrétoire est importante dans notre étude $(50 \%)$ pouvant être due à un biais dû au petit effectif.

Toutefois cette augmentation est à mettre en rapport avec l'existence de 15 fois plus d'anomalies du caryotype chez les azoospermes sécrétoires par rapport à la population générale comme nous l'avions déjà rapporté en accord avec d'autres auteurs.

Un patient a un phénotype masculin et une formule caryotypique $\mathrm{XX}$; l'étude génomique étant négative il est probable que si du matériel $\mathrm{Y}$ est présent chez ce patient expliquant son phénotype masculin, l'absence de matériel AZF explique son azoospermie. Un deuxième patient présente 
des micro-délétions dans les zones étudiées, cliniquement on note une hypotrophie testiculaire sans antécédent. Si l'on exclut les patients ayant une anomalie du caryotype nous retrouvons dans cette étude $11 \%$ de patients azoospermes sécrétoires présentant des microdélétions du bras long du chromosome $\mathrm{Y}$, ceci en accord avec d'autres auteurs.

En conclusion ces résultats en accord avec ceux de la littérature montrent que non seulement l'étude du caryotype est informative chez les patients ayant une azoospermie sécrétoire mais également la recherche des micro-délétions du bras long du chromosome Y. Ce diagnostic est primordial pour l'information du patient et le conseil génétique. En présence de micro-délétions de l'Y le patient doit être averti du risque de transmission à sa descendance mâle. Notre étude se poursuit avec l'inclusion de patients présentant une oligospermie. Par ailleurs l'étude phénotypique des patients ayant des micro-délétions du bras long de l'Y nous apparaît indispensable à la lumière de lien entre l'existence de délétions et la présence d'autres tableaux pathologiques.

-

\section{RECHERCHE DE DELETIONS MOLECU- LAIRES AU NIVEAU DU GENE DAZ CHEZ 22 PATIENTS INFERTILES}

\author{
F. Fellmann, C. Roux, M.C. Clavequin, J.L. \\ BRESSON
}

Service de Cytogénétique-Immunocytologie-Biologie du développement et de la Reproduction et

CNRS URA 561, CHU, Place Saint-Jacques, 25030 Besançon Cedex

\section{Introduction - Buts}

Le gène DAZ (deleted in azoospermia) a été identifié en 1995 par l'équipe de D. Page et est localisé en Yq11.23, dans l'intervalle 6 du chromosome $Y$. Des délétions de cette région génomique peuvent être mises en évidence par l'amplification de séquences génétiques courtes de localisation connue, et ont déjà pu être observées chez un certain nombre de sujets azoospermiques ou présentant une oligozoospermie sévère. Nous avons entrepris la recherche de délétions moléculaires de cette région chez des patients consultant dans l'Unité de Biologie de la Reproduction du CHU de Besançon.

\section{Matériel et Méthodes}

Quatre patients azoospermiques et 18 patients présentant une oligozoospermie sévère ont été étudiés. Le marqueur sY14 (gène SRY) a servi de témoin pour chacun des patients étudiés et neuf autres marqueurs STS spécifiques de la région Yq11 ont été amplifiés par PCR à partir de l'ADN génomique extrait d'un prélèvement sanguin. Quatre des STS testés correspondent à des séquences intra-géniques du gène $\mathrm{DAZ}$ (sY254, sY255, sY277, sY283), et une paire d'amorces amplifie directement un fragment de l'ADN de ce gène.

\section{Résultats - Discussion}

Un des patients testés, qui présente une oligozoospermie sévère $(<10000 \mathrm{spz} / \mathrm{ml})$, est délété pour l'ensemble des marqueurs du gène $\mathrm{DAZ}$, ainsi que pour les marqueurs sY155, plus proximal, et sY269, plus distal sur le bras long de l'Y. Un produit d'amplification de la taille attendue est en revanche observé pour les marqueurs YRRM2 et sY160. Les autres patients n'ont pas de délétions objectivables pour les marqueurs testés.

Ce résultat est un argument supplémentaire en faveur de la fréquence des remaniements du bras long du chromosome $\mathrm{Y}$ dans une population d'hommes infertiles. Cette pathologie est actuellement en cours d'évaluation mais devient un élément à prendre en compte pour le diagnostic étiologique des stérilités sécrétoires et surtout dans la prise en charge de ces patients, pour la plupart candidats à des techniques d'AMP par ICSI.

\section{L'UTILISATION DE SPERMATIDES EN FECONDATION IN VTTRO : FICTION OU REALITE ?}

\author{
I. Virant-Kiun, B. Zorn, A. Ihan, H. Meden- \\ VRTOVEC, T. TOMAZEVIC
}

Service de Gynécologie-Obstétrique - Centre Clinique Universitaire de Ljubljana -Slovénie

\section{Introduction}

Wanderzwalmen rapporte en 1995 la fécondation humaine d'ovocytes par des spermatides allongées et le clivage embryonnaire jusqu'au stade quatre cellules. Cela a été confirmé par la 
naissance de deux enfants à la suite de l'injection ovocytaire de spermatides rondes extraites de l'éjaculat (Tesarik et al, NEJM, 1995). Il semble que l'injection intracytoplasmique de spermatides de l'éjaculat d'hommes azoospermiques puisse devenir le seul traitement possible chez les patients atteints d'azoospermie non-obstructive dont l'exploration testiculaire se sera révélée infructueuse. Ainsi s'enquérir de la qualité des spermatides devient un préalable indispensable avant d'envisager leur utilisation en fécondation in vitro.

Le but du travail a été d'étudier la possibilité d'injecter les spermatides dans les ovocytes humains. Pour cela, nous avons analysé l'éjaculat de patients atteints d'azoospermie non-obstructive .

\section{Méthodes}

Dans ce groupe de 37 patients azoospermiques, les spermatides ont été isolées par la méthode de gradients discontinus de Percoll en 5 phases $(100 \% /, 80 \% /, 70 \% /, 50 \% /, 40 \%)$. Pour chaque patient, les spermatides de la fraction $\mathrm{P} 70$ ont été comptées en chambre de Makler.

Chez 7 patients, les noyaux ont été colorés par le Giemsa pour évaluer le pourcentage de spermatides bi- et multinucléées qui représentent des formes anormales. On connaissait le caryotype lymphocytaire de tous ces patients.

L'éjaculat de 5 patients a fait l'objet d'une analyse par cytométrie de flux de la répartition du DNA des cellules germinales.

\section{Résultats}

Nous avons retrouvé des spermatides dans les éjaculats de tous ces hommes azoospermiques. La concentration moyenne de spermatides a été de $9 \times 10^{6} / \mathrm{ml}$. Chez un patient, un taux anormalement élevé $(80 \%)$ de spermatides bi- ou multinucléées a été retrouvé. Chez les autres patients, ces spermatides anormales $n^{\prime}$ ont représenté que moins de $10 \%$ de l'ensemble.

Chez 2 patients, l'étude cytométrique de l'histogramme du DNA se distinguait par une prise anormale de fluorescence entre le pic d'haploïdie et celui de diploïdie pouvant traduire une décondensation anormale de chromatine. Les patients avec spermatides bi- ou multinucléées et ceux avec une hypothétique décondensation chromatinienne avaient tous un caryotype normal.

\section{Conclusion}

La quantité de formes bi- ou multinucléées et/ou de décondensation chromatinienne semblent être des critères de qualité de la spermatide et de sélection de celle-ci avant d'envisager une éventuelle injection ovocytaire.

\section{METHODES D'OBTENTION DE GAMETES EN VUE D'ICSI}

\section{LA RECHERCHE IN EXTREMIS DE SPER- MATOZOÏDES DANS L'EJACULAT PER- MET-ELLE DEVITER, DANS LES AZOOSPER- MIES NON-OBSTRUCTIVES, UN PRELE- VEMENT TESTICULAIRE DE SPERME POUR LA FERTILISATION ASSISTEE ?}

Y. SOFFER*, D. STRASSBURGER**, S. KAUfmaN*, A. RAZIEL $^{* *}$, S. FRIEDLER**, D.KomaRovSKI**, O. BEM $^{* *}$, I. BuKovSKI ${ }^{\circ}$, R. RoN-EL ${ }^{* *}$.

*Centre de Fertilité Masculine; **Centre de FIV; ${ }^{\circ}$ Service d'obstétrique et de gynécologie, Centre médical Assaf Harofé.Faculté de médecine Sackler; Université de Tel Aviv. Israël.

Aujourd'hui, les hommes souffrants d'une azoospermie non-obstructive peuvent souvent féconder leurs conjointes grâce à un prélèvement chirurgical de spermatozoïdes testiculaires et une fécondation assistée (ICSI). Est-il cependant possible d'éviter cette intervention?

\section{Objectifs}

Dans les azoospermies non-obstructives :

- Tenter une recherche in extremis de spermatozoïdes dans l'éjaculat avant toute intervention testiculaire pour lCSI.

- Evaluer la réduction des interventions sur le testicule grâce à cette recherche.

- Comparer les résultats de l'ICSI selon l'origine séminale ou testiculaire des spermatozoïdes injectés.

\section{Matériel et Méthodes}

Dans un groupe de 24 cas d'azoospermie non-obstructive avec plusieurs recherches infructueuses de spermatozoïdes dans l'éjaculat, un prélèvement 


\begin{tabular}{lccccc}
\hline Recherche & séminale cas & âge & FSH IU/L & Testostérone & \% fécondation \\
\hline Succès & 6 & $33.3 \pm 4.6$ & $27.5 \pm 0.5$ & $9 \pm 5.0$ & $46 \%$ \\
Echec* & 18 & $34.5 \pm 6.8$ & $19.5 \pm 8.2$ & $11 \pm 2.3$ & \\
\hline *Prélèvement & testiculaire cas & âge & FSH IU/L & Testostérone & \% fécondation \\
\hline & Succès 9 & $32 \pm 5.4$ & $24.3 \pm 4.0$ & $11.6 \pm 5.7$ & $48 \%$ \\
& Echec 9 & $34 \pm 3,4$ & $13.6 \pm 7.4$ & $12.2 \pm 4.7$ & \\
\hline
\end{tabular}

chirurgical de spermatozoïdes testiculaires pour ICSI a été projeté. Le jour prévu de l'intervention, un ou deux éjaculats sont demandés. Le sperme est dilué et centrifugé à $1800 \mathrm{~g}$ pendant $30 \mathrm{~m}$. Le culot de centrifugation est alors resuspendu. Après vérification de routine de l'absence de tout spermatozoïde en cellule de Makler, le culot est divisé en gouttes minuscules de 44 microlitres légèrement étalées sur le fond d'une boite de Pétri et minutieusement examinées en microscopie inversée sous huile de paraffine. Les spermatozoïdes découverts sont transférés au fur et à mesure dans des gouttes de polyvynil pyrolidone. Si un nombre suffisant de spermatozoïdes pour micro-injection est trouvé, le prélèvement testiculaire est annulé.

\section{Résultats}

Cette recherche séminale a permis de trouver un nombre suffisant de spermatozoïdes pour l'ICSI dans six cas $(25 \%)$. Chez les $18(75 \%)$ autres, un prélèvement testiculaire de spermatozoïdes a été nécessaire, mais il n'a réussi que dans 9 cas (50\%) (Tableau 1).

L'âge moyen des sujets est partout similaire. Le taux du FSH ne prédit pas la découverte de spermatozoïdes séminaux ou testiculaires. Lorsque la micro-injection des ovocytes est faite, l'origine des spermatozoïdes injectés n'influence pas le taux de fécondation.

\section{Conclusions}

Dans les azoospermies non-obstructives, la recherche in extremis de spermatozoïdes dans l'éjaculat donne des résultats souvent surprenants mais imprévisibles. Cette procédure a réussit dans $25 \%$ de nos cas, et nous a permis de réduire substantiellement le nombre des prélèvements testiculaires nécessaires; elle est donc à recommander, d'autant plus que les spermatozoïdes qu'elle découvre, témoignent en microinjection, d'un pouvoir fécondant semblable à celui des spermatozoïdes testiculaires.

\section{LA CRYO-PRESERVATION DES SPERMA- TOZOÏDES PRELEVES SUR LES TESTI- CULES DANS LES AZOOSPERMIES NON- OBSTRUCTIVES}

\author{
Y. SOFFER*, S. FRIEDLER ${ }^{* *}$, A. RAZIEL**, D. \\ Strassburger ${ }^{* *}$, S. Kaufman* ${ }^{*}$ D. Komarovs- \\ $\mathrm{KI}^{* *}$, O. BERN ${ }^{* *}$, I. BuKOVSKI ${ }^{\circ}$, R. RON-EL R* $^{* *}$ \\ *Centre de Fertilité Masculine, ${ }^{* *}$ Centre de FIV, \\ 'Service d'obstétrique et de gynécologie, Centre \\ médical Assaf Harofé.Faculté de médecine Sack- \\ ler; Université de Tel Aviv. Israël.
}

La congélation des spermatozoïdes testiculaires a été pratiquée avec succès dans des azoospermies non-obstructives. La possibilité de congeler des spermatozoïdes prélevés des testicules en vue de fécondations assistées (ICSI) futures est d'autant plus estimable qu'il s'agit souvent de cas avec insuffisance germinative grave et petits testicules que des prélèvements biopsiques répétés menacent de lésions tissulaires et fonctionnelles surajoutées.

\section{Objectif}

Evaluer l'intérêt de la cryo-préservation de spermatozoïdes prélevés des testicules dans des cas d'azoospermie non-obstructive pour leur utilisation dans des cycles ultérieurs de fécondation assistée.

\section{Matériel et Méthodes}

Dans un groupe de 16 cas d'azoospermie non-obstructive, un prélèvement testiculaire de spermatozoïdes a permis de pratiquer une fécondation assistée avec des spermatozoïdes frais. Dans six de ces cas, il a également été possible de congeler la suspension des spermatozoïdes surnuméraires selon le protocole de routine de congélation du sperme. De nouveaux cycles de fécondation assistée ont pu être pratiqués avec ces spermato- 


\begin{tabular}{|c|c|c|}
\hline Spermatozoides utilisés & frais & cryopréservés \\
\hline nombre de couples & 16 & 6 \\
\hline " de cycles d'ICSI & 20 & 11 \\
\hline " d'ovocytes injectés & 174 & 105 \\
\hline "d'ovocytes injectés/cycle & $8.6 \pm 3.9$ & $9.5 \pm 5.8$ \\
\hline " d'ovocytes fécondés & $82(47,1 \%)$ & $45(44,4 \%)$ \\
\hline " d'embryons de bonne qualité & $723(95,1 \%)$ & $39(\mathrm{~g} 7,5 \%)$ \\
\hline " de transferts d'embryons & 18 & 8 \\
\hline " d'embryons transferés & 61 & 28 \\
\hline " + embryons cryo-préservés & 3 & 4 \\
\hline " d'embryon/transfert & $3.4 \pm 1.2$ & $3.5 \pm 1.7$ \\
\hline " de grossesse/transfert & $4 / 18(22 \%)$ & $2 / 8(25 \%)$ \\
\hline Taux d'implantation/embryon & $4 / 61(6.1 \%)$ & $2 / 28(7.1 \%)$ \\
\hline
\end{tabular}

zoïdes cryo-préservés. Les résultat des cycles d'ICSI pratiqués avec des spermatozoïdes testiculaire frais ou cryo-préservés ont été comparés.

\section{Résultats}

Le tableau 1 montre que les résultats de la fécondation assistée avec du sperme testiculaire frais ou cryo-préservé sont similaires en termes de taux de fécondation, d'implantation et de grossesses ainsi que de qualité des embryons.

\section{Conclusion}

Dans les azoospermies non-obstructives où l'on ne trouve pas dans l'éjaculat de spermatozoïdes pour micro-injection, un prélèvement des testicules est requis ; la cryopréservation des spermatozoïdes testiculaires surnuméraires doit alors être envisagée. Cette procédure permet de réitérer les cycles de fécondation assistée et de cumuler les chances de grossesse sans pour autant répéter les interventions testiculaires. La cryo-préservation des spermatozoïdes testiculaires est recommandée non seulement à la suite d'un prélèvement thérapeutique mais aussi après toute biopsie testiculaire diagnostique.

\section{$\bullet \bullet \bullet$}

\section{LE PRELEVEMENT TESTICULAIRE A L'AIGUILLE : TECHNIQUE D'AVENIR}

C. Wittemer, J. Ohl, K. Bettahar-Lebugle, C. FATH*, L. Moreau, D. JaCQMin*, P. DellenBach

Département de PMA, CMCO, Schiltigheim

* Service d'urologie, Hospices Civils, Strasbourg

\section{Introduction - Buts}

L'ICSI a donné un second souffle au traitement des azoospermies excrétoires. Elle a permis d'améliorer les résultats, que le sperme soit d'origine épididymaire ou testiculaire. Le prélèvement des spermatozoïdes épididymaires se faisait traditionnellement au cours d'une intervention en technique microchirurgicale souvent longue. Au niveau testiculaire un fragment de pulpe était prélevé par biopsie.

Récemment une technique de prélèvement des spermatozoïdes testiculaires par simple ponction transcutanée a été décrite puis développée avec des résultats intéressants grâce à l'ICSI qui nécessite un nombre très restreint de spermatozoïdes mobiles.

\section{Matériel et méthodes}

Entre octobre 95 et octobre 96, nous avons proposé ce prélèvement testiculaire transcutané avec ICSI à 30 couples présentant une infécondité due à une azoospermie excrétoire (biopsie préalable) au cours de 33 tentatives.

L'azoospermie résulte d'une agénésie bilatérale des déférents (ABCD) dans 15 cas, elle est posttraumatique dans 7 cas et post-infectieuse dans 4 cas. L'azoospermie résulte d'une vasectomie dans un cas, d'une hémicastration pour cancer dans un cas. L'azoospermie s'accompagne d'une FSH élevée dans 2 cas.

Pour les cas d'agénésie des déférents, une analyse du gène CFTR est réalisée chez l'homme et sa conjointe. Ces couples bénéficient alors 
d'un conseil génétique pour estimer le risque résiduel d'avoir un enfant atteint de mucoviscidose.

Chez les conjointes le bilan est normal dans 19 cas, dans 8 cas le bilan hormonal est perturbé. On note également deux cas d'anomalie cervicale et un cas de stérilité tubaire.

Les protocoles de stimulation ovarienne et de prélèvement ovocytaire sont ceux utilisés classiquement en FIV.

La ponction testiculaire transcutanée est pratiquée sous anesthésie générale à l'aide d'une aiguille de 18 Gauges.

La seule difficulté dans la mise en œuvre de l'ICSI réside dans la recherche des quelques spermatozoïdes mobiles dans une suspension riche en débris cellulaires divers.

\section{Résultats}

Le prélèvement testiculaire a permis d'obtenir suffisamment de spermatozoïdes mobiles pour réaliser l'ICSI dans $88 \%$ des cas (29 tentatives). Une biopsie chirurgicale complémentaire a été effectuée dans $12 \%$ des cas (4 tentatives).

32 transferts embryonnaires (de 1 à 4 embryons) ont permis d'initier 7 grossesses.

Deux grossesses sont en cours d'évolution ( $>5$ mois), deux patientes ont accouché d'un enfant en bonne santé et deux grossesses se sont soldées par une fausse-couche spontanée.

\section{Conclusion}

Le prélèvement testiculaire transcutané présente des avantages évidents par rapport au prélèvement chirugical classique : simplicité, rapidité, innocuité et répétabilité.

Pour avoir de bonnes chances de succès, une biopsie testiculaire préalable montrant la conservation d'une bonne spermatogénèse est indispensable.

\section{ICSI ET AZOOSPERMIE : RESULTATS}

\section{ICSI ET AZOOSPERMIE}

\section{BAILLY* , F. MERLET**, J-P Bisson **}

*Service Gynécologie-Obstétrique ; **Service Histologie et Biologie de la Reproduction - CHI Poissy

\section{But}

Réflexions pour un protocole diagnostique et thérapeutique, à propos de 16 cas d'azoospermie.

\section{Sujet}

16 hommes azoospermiques (absence de spermatozoïde dans le culot de centrifugation à au moins 2 examens) demandeurs d'ICSI, de leur propre chef ou sur conseil médical, certains ayant eu recours au CECOS.

\section{Méthode}

Le bilan étiologique vise à définir la nature sécrétoire ou excrétoire, acquise ou constitutionnelle de l'azoospermie. Il comprend : la recherche des antécédents, un examen clinique (volume, mesure et consistance testiculaires, palpation des épididymes et des déférents, TR) complété par un examen échographique, la prise en compte des "petits signes" spermatiques (identité des cellules rondes, volume de l'éjaculat, $\mathrm{pH}$ ) le dosage des marqueurs séminaux, de gonadotrophines sériques, le caryotype (sauf en cas d'azoosperrnie à l'évidence excrétoire).

Les prélèvements, en conditions chirurgicales avec $\mathrm{AG}$ ou 1 fois sous rachi-anesthésie, sont réalisés en préalable ou simultanément à la ponction ovocytaire si la positivité du recueil paraît hautement probable. La recherche des spermatozoïdes, immédiate, n'est pas poursuivie au-delà de 3 biopsies par testicule. Ces spermatozoïdes sont utilisés, selon leur nombre, directement après lavage en $\mathbf{B} 2$ ou après Percoll. En cas de recueil très positif (quelques milliers de spermatozoïdes estimés) une "micro congélation" en cryoprotecteur sans jaune d'oeuf est pratiquée.

\section{Résultats}

7 azoospermies ont été étiquetées excrétoires ; 1 grossesse a été obtenue avec spermatozoïdes tes- 
ticulaires, recueillis simultanément à la ponction ovocytaire, 1 grossesse avec spermatozoïdes épididymaires congelés, 2 cas avec échec après transferts d'embryons avec spermatozoïdes épididymaires et testiculaires, 2 cas sont en attente, après congélation de spermatozoïdes épididymaires.

Sur 9 azoospermies sécrétoires, 1 grossesse a été obtenue avec spermatozoïdes testiculaires, 8 échecs de recueil spermatique avec aplasie germinale confirmée à l'histologie.

\section{Discussion}

Plutôt que sur les résultats bruts, qui confirment l'intérêt de l' ICSI surtout dans les azoospermies excrétoires, la réflexion est d'ordre méthodologique.

1. l'origine génétique de certaines azoospermies implique de distinguer entre cause acquise et constitutionnelle; hors la certitude d'une cause acquise, le caryotype s'impose et la recherche des mutations de la protéine CFTR devra être discutée, la symptomatologie spermatique ne paraissant pas stéréotypée. De plus, la découverte des micro délétions de l'Y (gène DAZ) devra sans doute à terme être prise en considération.

2. l'appréciation de la faisabilité, surtout dans l'azoospermie sécrétoire, n'est pas aisée ; il semble que la consistance et la taille des testicules mesurée à l'orchidomètre ou par échographie, ainsi que le dosage de la FSH sérique soient de bons critères : au dessous de $6 \mathrm{ml}$, avec une FSH haute, le risque d'échec paraît élevé, même après biopsies multiples dont le nombre devrait être limité. Cette incertitude quant au recueil pose la question de l'intérêt des prélèvements exploratoires hors stimulation et du perfectionnement des micro-congélations.

3. la réalisation de ces biopsies à des fins thérapeutiques devrait permettre un certain nombre d'études fondamentales : analyse de la méiose, microscopie électronique des spermatogenèses déficientes, recherche de critère d'identification des spermatides en phase liquide.

4. enfin, la réalisation d'ICSI avec spermatozoïdes du conjoint alors qu'un enfant est né dans le couple par l'intermédiaire du CECOS devrait être discutée.
MICRO INJECTIONAVEC SPERMATOZOIDES TESTICULAIRES : COMPARAISON AVEC LES RESULTATS GLOBAUX DE L'ICSI AU CENTRE AMP DE LA MATERNITE HOPITAL SAINTE CROIX DE METZ (57)

\section{J.P. RAGaGE*, T. CassieR*, J.M. BouschbaChER*, T. SCHWEITZER*, F. LESTRADE*, R. WASELS**, B. KUNTZEL** \\ *Centre de lutte contre la stérilité Matemité Hôpi- tal Sainte Croix 8 rue des Récollets $57000 \mathrm{Metz}$ \\ **LABM Stahl-Kuntzel, 21 Place du Quarteau $57000 \mathrm{Metz}$.}

Le but de ce travail est de comparer les résultats obtenus avec des spermatozoides recueillis par dilacération de biopsies testiculaires (TESE) aux résultats de l'ICSI avec sperme éjaculé au sein de notre centre d'AMP au cours de l'année 1995.

L'ICSI avec sperme éjaculé a été pratiquée au cours de 106 cycles pour les indications classiques (OATS FIV impossible, anticorps antispermatozoïdes, échecs de FIV pour OAT, échec inexpliqué de FIV). L'ICSI avec sperme testiculaire a été pratiquée au cours de 10 cycles pour azoospermie excrétoire.

La biopsie testiculaire est réalisée après anesthésie locale et permet de ramener $90 \mathrm{~mm} 3 \mathrm{de}$ tissu testiculaire immédiatement plongé dans du milieu de B2 de Menezzo.

Le tissu testiculaire est dilacéré en boite de pétri à l'aide de deux lames de microscopes ou de deux aiguilles type IM. Après centrifugation 5 minutes à $300 \mathrm{~g}$ le culot est remis en suspension dans une goutte de B2 Menezzo. Un mini percoll $90 / 70 / 70$ peut également être pratiqué selon la richesse du prélèvement.

Après ponction par voie endo vaginale, les ovoytes sont mis à maturer deux heures; la décoronisation a lieu dans une solution de hyaluronidase à $80 \mathrm{Ul} / \mathrm{ml}$ de milieu de $\mathrm{B} 2$ de Menezzo pendant 30 secondes. La micromanipulation se déroule sous huile (utilisant la technique d'extra drop en cas de sperme testiculaire) en boite de pétri. Le protocole utilisé fait appel à l'écrasement du flagelle et aspiration du cytoplasme ovocytaire.

Les résultats obtenus ne montrent pas de différence significative entre les deux séries (Tableau 1). 
Nombre de tentatives

Nombre de transferts

Nombre de congélations

Nombre d'ovocytes recueillis

Nombre d'ovocytes techniqués

Nombre d'embryons obtenus

Nombre d'embryons tranférés

Nombre moyen d'embryons par transfert

Nombre d'embryons congelés

Nombre de grossesses

taux par ponction

taux par transfert

$\begin{array}{cc}106 & \mathbf{1 0} \\ 98 & \mathbf{1 0} \\ 34 & \\ 932 & 107 \\ 795 & \mathrm{~B} 7 \\ 401(50,4 \%) & 49(\mathbf{5 6 , 3 \% )} \\ 223 & 19 \\ 2,27 & 1,9 \\ 109 & 27 \\ 37 & 3 \\ 35 & 30 \% \\ 37,7 & 30 \%\end{array}$

En conclusion l'ICSI réalisée avec des spermatozoïdes obtenus par dilacération de biopsies testiculaires nous permet désormais de traiter les cas d'azoospermies excrétoire avec des taux de succès acceptables. Cependant il faut rester vigilant quant aux conséquences possibles de ces biopsies sur le statut testiculaire (vascularisation, spermatogénèse) et éviter la multiplication du geste.

\section{- \\ GROSSESSE OBTENUE APRES INJECTION INTRAOVOCYTAIRE DE SPERMATOZOIDES TESTICULAIRES CRYOCONSERVES ET IMMOBILES APRÈS DECONGELATION}

\author{
N. Rives*, L. Sibert**, B. ClavieR ${ }^{\circ}$, V. Dela- \\ BROYE*, S. MAZURIER*, B. MACE* \\ *Laboratoire d'Histologie ; **Service d'Urologie ; \\ - Service de Gynécologie, CHU Charles Nicolle, \\ 76031 Rouen cedex
}

L'injection intraovocytaire d'un spermatozoïde constitue maintenant le traitement palliatif des infertilités masculines sécrétoires ou excrétoires. Les taux de fécondation et de grossesse obtenus avec des spermatozoïdes épididymaires sont considérablement améliorés par cette technique. Cependant, l'isolement de spermatozoïdes épididymaires peut échouer et le testicule constitue alors l'unique source de spermatozoïdes.

Nous rapportons la première observation de la littérature d'une grossesse obtenue chez une femme âgée de 33 ans après microinjection de spermatozoïdes testiculaires cryoconservés et immobiles après décongélation.

\section{Matériel et Méthodes}

Ce couple a été suivi dans notre centre pour l'exploration d'une azoospermie excrétoire avec agénésie bilatérale des canaux déférents. Le mari, âgé de 38 ans, avait subi deux explorations scrotales 10 et 20 ans auparavant à la fois pour apprécier la qualité de la spermatogénèse mais aussi pour douleurs testiculaires dans le cadre d'une épididymite gauche. Le jour du prélèvement épididymaire en vue de la microinjection, l'abord chirurgical a révélé la présence de multiples adhérences et d'une agénésie quasi complète de la tête épididymaire. Les spermatozoïdes prélevés à ce niveau et plus en amont étaient tous immobiles associés à de nombreux leucocytes. Une biopsie testiculaire fut de ce fait réalisée. Après dissection sous loupe de tubes séminifères en milieu B2 (INRA Menezzo,), le sumageant subit une migration sur un Percoll (KABI Pharmacia,) deux couches $(70 \%, 90 \%)$ et les spermatozoïdes non utilisés furent congelés en milieu Freezing (IRVINE SCIENTIFIC,) puis décongelés à $37^{\circ} \mathrm{C}$ pendant 5 minutes.

\section{Résultats}

La première tentative réalisée avec les spermatozoïdes testiculaires frais et de faible mobilité (mouvement de tremblement) échoua. A la deuxième tentative effectuée quatre mois plus tard, les spermatozoïdes testiculaires cryoconservés étaient immobiles après décongélation et pendant tout le déroulement de l'ICSI.

Au total, 16 ovocytes furent recueillis, 11 avec un globule polaire furent injectés. Des taux de fécondation de $56 \%$ et de clivage de $100 \%$ furent obtenus. Trois embryons transférés aboutirent à 
une grossesse simple actuellement en cours (deuxième trimestre), les trois autres embryons furent congelés.

\section{Conclusion}

Il s'agit à notre connaissance de la première observation d'une grossesse obtenue avec des spermatozoïdes testiculaires immobiles après décongélation. Ce résultat nous encourage à cryoconserver les spermatozoïdes testiculaires lorsqu'une biopsie est réalisée chez des patients présentant une azoospermie sécrétoire ou excrétoire non seulement pour éviter la répétition des prélèvements mais aussi pour permettre de différer le prélèvement urologique par rapport à la ponction ovocytaire. La congélation peut être envisagée même si la mobilité des spermatozoïdes est très faible.

La mobilité ne constitue pas un facteur d'appréciation de la vitalité des spermatozoïdes et immobilité n'est pas synonyme de nécrospermie. Une amélioration des techniques d'appréciation de la vitalité, comme l'"hypoosmotic swelling test“, et des techniques de congélation doit être envisagée.

$\bullet$

\section{INTERETS DE L'ICSI AVEC RECUEIL CHIRURGICAL DE SPERMATOZOIDES DANS LES AZOOSPERMIES OBSTRUCTIVES, SECRETOIRES ET LES ANEJACULATIONS}

WOLF J.Ph.*, ThIOUNN N.**, IZARD V. ${ }^{\circ}$ PoIrot C.*, Bouker A.**, Lebon C.***, Debré B.**, JARDIN A. ${ }^{\circ}$, ZoRn J.R. ${ }^{\circ}$, EPElboin S. ${ }^{\circ 0}$, JolanNeT P.*

* Laboratoire de Biologie de la Reproduction, **, ${ }^{\circ}$ Services d'Urologie, ${ }^{* * *}$ Cecos, ${ }^{\circ},{ }^{\circ 00}$ Services de Médecine de la Reproduction ; Hopital Cochin, Kremlin Bicetre et Saint Vincent de Paul. Paris

\section{Introduction et buts.}

Le recueil chirurgical de spermatozoïdes permet la fécondation par microinjection intracytoplasmique (ICSI) dans des cas d'azoospermies obstructives et sécrétoires ou les anéjaculations. Le but de cette étude est de déterminer les conditions de la prise en charge de ces patients ainsi que les résultats obtenus en fonction des étiologies et des conditions $\mathrm{du}$ recueil spermatique.

\section{Matériel et Méthodes}

Les patients ont été pris en charge dans le cadre d'un réseau multidisciplinaire. Le bilan systématique a compris, outre le spermogramme, une investigation bactériologique urogénitale, un dosage de la FSH et une analyse de la biochimie séminale. Une étude des mutations des gènes CFTR et un conseil génétique ont été réalisés préalablement à la tentative en cas d'agénésie épididymo-déférentielle et/ou de mucoviscidose.

Dans le cadre des azoospermies obstructives et dans les anéjaculations le recueil de spermatozoïdes a été effectué sous anesthésie générale par scrototomie. Les spermatozoïdes ont été recueillis dans répididyme à l'aide d'un microcathèter adapté sur une seringue éventuellernent après massage, en amont et à distance de l'obstacle ou au niveau du déférent. Exceptionnellement le prélèvement a été fait au niveau des cônes efférents dans les cas d'obstructions haut situées. La qualité du recueil a été contrôlée par un examen extemporané. Dans les cas d'agénésie épididymo-déférentielle avec spermatogenèse très altérée, une épididymectomie partielle avec expression de la pièce chirurgicale a permis de recueillir le maximum de spermatozoïdes. Pour les azoospermies sécrétoires les biopsies ont été réalisées de façon synchrone avec la réalisation de la microinjection.

\section{Résultats et discussion (Tableau 1).}

Avec un taux de grossesse de $18 \%$ par tentative et de $21 \%$ par transfert, l'association du recueil chirurgical de spermatozoïdes et de microinjections intracytoplasmiques présente une réelle solution thérapeutique pour les couples. Cependant dans plus de 50\% des azoospermies sécrétoires aucun spermatozoide n'a été trouvé lors de la tentative. Il importe donc de mieux définir les cas susceptibles de bénéficier de ce traitement afin de ne pas s'exposer à une intervention chirurgicale et une stimulation ovarienne inutiles. I,e taux de fécondation et de clivage embryonnaire dans cette indication sont par ailleurs nettement inférieurs à ce qu'ils sont pour le sperme épididymaire. Celui-ci donne des taux de fécondation comparables à ceux obtenus avec du sperme éjaculé. Il est intéressant de noter que les taux de fécondation et de grossesse sont identiques entre le sperme épididymaire frais et congelé. Cela justifie que lors de toute intervention sur la voie séminale, une congélation de sperme épididymaire soit effectuée. 
Tableau 1 :

\begin{tabular}{lccccccc}
$\begin{array}{l}\text { Origine du } \\
\text { sperme }\end{array}$ & \multicolumn{2}{c}{$\begin{array}{c}\text { Tentatives } \\
\text { N,avec ICSI }\end{array}$} & Ovocytes & $\begin{array}{c}\text { Embryons } \\
\mathbf{N}\end{array}$ & $\begin{array}{c}\text { Transferts } \\
\mathbf{N}(\%)\end{array}$ & $\begin{array}{c}\text { Grossesse } \\
\mathbf{N}\end{array}$ & $\begin{array}{c}\text { Embryons } \\
\text { congelés }\end{array}$ \\
DEF & 3 & 3 & 17 & $9(53)$ & 3 & 0 & 3 \\
DEFCONG & 9 & 9 & 66 & $33(50)$ & 7 & 1 & 12 \\
EPID & 23 & 23 & 180 & $89(49)$ & 22 & 5 & 35 \\
EPIDCONG & 24 & 24 & 173 & $84(48)$ & 23 & 5 & 30 \\
TESTI & 15 & 7 & 88 & $24(27)$ & 7 & 2 & 4 \\
Total & $\mathbf{7 4}$ & $\mathbf{6 4}$ & $\mathbf{5 2 4}$ & $\mathbf{2 3 9 ( 4 6 )}$ & $\mathbf{6 2}(\mathbf{9 2 \%})$ & $\mathbf{1 3}(\mathbf{2 1 \% )}$ & $\mathbf{8 4}$
\end{tabular}

DEF: sperme deférentiel; DEFCONG: sperme déférentiel congelé, EPID: sperme épididymaire; EPIDCONG: spetme épididymaire congelé, TESTI: sperme testiculaire. * ovocytes en métaphase 2 . \$ Nombre d'embryons et pourcentage de fécondation des ovocytes microinjectés.

\section{ACTUALITE EN UROLOGIE ANDROLOGIE}

\section{CONTROLE DE LA FONCTION ERECTI- LE}

\section{APPROCHE MORPHOLOGIQUE DE LA MODULATION OCYTOCINERGIQUE DE L'ERECTION CHEZ LE RAT}

F. Veronneau-Longueville*, Y. TANG*, O. RAMPIN $^{* *}$, G. BENOIT*, A. JARDIN*, M.J.FREUND-MERCier $^{\circ}$, A. Calas ${ }^{\circ}$. F. Giuliano*

${ }^{*} \mathrm{CHU}$ de Bicêtre, Le Kremlin-Bicêtre **INRA Jouy-en-Josas

${ }^{\circ}$ CNRS URA 1446, ULP, Strasbourg ${ }^{\circ} \mathrm{CNRS}$ URA 1488, Paris

\section{Introduction}

Les neurones préganglionnaires proérectiles sont groupés dans le noyau parasympathique sacré (NPS) de la moelle L6-Sl chez le rat. Ces neurones sont activés par des informations nerveuses d'origine périphérique ou centrale. Le noyau paraventriculaire de l'hypothalamus (PVN), dont la stimulation provoque l'érection chez le rat, apparait comme un centre de contrôle supraspinal de l'érection. Les neurones ocytocinergiques (OT) du PVN projettent vers la moelle.

\section{But}

Nous avons recherché la présence de projections OT sur les neurones du NPS (nNPS).

\section{Matériels et Méthodes}

Les nNPS sont identifiés sur des coupes de moelle épinière par transport axonal rétrograde de WGA-HRP appliquée sur le nerf pelvien 48 heures avant le sacrifice des rats. Les fibres OT sont mises en évidence sur les mêmes coupes par l'immunocytochimie. Des coupes transversales de la moelle L6-Sl sont incubées à $4^{\circ} \mathrm{C}$ en présence d'un antagoniste ocytocinergique radioiodé hautement spécifique (d(CH2) 5(Tyr(Me) 2, Thr4, Tyr-NH29) OVT) puis traitées pour l'autoradiographie et l'histoautoradiographie.

\section{Résultats}

Les fibres OT sont présentes dans la corne dorsale, la commissure grise dorsale et le NPS. Des synapses entre fibres OT et les nNPS sont révélées par microscopie électronique. Des sites de liaison spécifique de l'OT sont mis en évidence dans la corne dorsale, la commissure grise dorsale et le NPS.

\section{Conclusion}

Les nNPS reçoivent une innervation OT. Ces données fournissent un support morphologique à l'étude du contrôle médullaire de l'érection par l'OT. 


\section{VASCULARISATION ARTERIELLE DU PENIS : NOUVELLES DONNEES ANATO- MIQUES ET IMPLICATIONS CLINIQUES}

\author{
S. Droupy*,**, G. Benoit*,**, F. GiUliano*, A. \\ JARDIN* \\ *Service d'Urologie du CHU de Bicêtre et Labo- \\ ratoire de chirurgie expérimentale. Université \\ Paris-Sud. \\ **Institut d'Anatomie des Saints-Pères. Univer- \\ sité Paris V. Paris.
}

\section{Objectifs}

Les variations d'origine des artères du pénis: artères honteuses internes accessoires (AHA) sont une entité controversée tant du point de vue de leur réalité anatomique que de leur rôle dans la survenue d'impuissance d'origine artérielle après chirurgie d'exérèse pelvienne. En ce qui concerne la distribution des artères au sein des corps érectiles, l'existence de shunts cavernospongieux tels qu'ils ont été décrits par $\mathrm{G}$. Wagner (The Lancet, Feb.20, 1982.416-418) reste sans explication physiologique. Nous avons étudié de façon exhaustive les voies artérielles de l'érection en nous attachant plus particulièrement à décrire les variations d'origine et les voies de communications vasculaires entre corps caverneux et spongieux afin de préciser le mode d'action de substances pharmacologiques injectées par voie infra-urétrale (MUSE) ainsi que les implications chirurgicales de voies artérielles d'origine supralévatorienne.

\section{Matériels et Méthodes}

Nous avons disséqué les artères pelviennes et péniennes de 20 cadavres frais de sexe masculin, âgés de 47 à 84 ans, après injection artérielle de latex coloré. Chez 3 sujets le corps spongieux a été injecté de latex coloré différemment. La dissection du pénis a été réalisée ex situ sous loupe binoculaire. Les corps caverneux et le corps spongieux ont été ouverts latéralement afin de disséquer les artères caverneuses et spongieuses ainsi que leurs branches de division. Le corps spongieux a ensuite été libéré des corps caverneux afin de mettre en évidence les anastomoses entre les deux systèmes vasculaires.

\section{Résultats}

Les AHA ont été trouvées chez 17 des 20 sujets. Elles naissaient de l'artère vésicale inférieure, de l'artère obturatrice et rarement de l'artère honteuse externe superficielle. Elles cheminent sur les faces antéro-latérales de la prostate sous le plexus péri-prostatique de Santorini et en dedans des nerfs caverneux. Elles donnent le plus souvent plusieurs branches terminales: artères caverneuses $(70 \%)$, artères dorsales $(20 \%)$ et artères bulbouretrales (10\%). Dans trois cas ces artères étaient la seule vascularisation artérielle des corps érectiles, les artères honteuses internes se terminant dans le périnée. Nous avons classé ces variations en trois types: Type I dans lequel la vascularisation du pénis est issue de l'artère honteuse interne $(3 / 20)$, Type II dans lequel les artères honteuses internes et les AHA participent à la vascularisation du pénis (14/20) et le Type III dans lequel seules les AHA se destinent au pénis (3/20).

6 à 10 anastomoses entre les artères caverneuses et le réseau artériel spongieux ont été observées sur chacun des spécimens examinés. Ces artères naissaient à intervalles réguliers de l'artère caverneuse, traversaient verticalement l'albuginée pour pénétrer le corps spongieux et s'anastomoser avec le réseau artériel spongieux. Le diamètre de ces artères variait de 0.3 à 1 $\mathrm{mm}$. L'injection $\mathrm{du}$ corps spongieux n'a permis de mettre en évidence aucune communication veineuse entre corps spongieux et caverneux.

\section{Discussion}

L'incidence élevée des AHA, leur affinité particulière pour les corps caverneux et leur situation dans le pelvis permettent de comprendre que l'interruption de ces flux artériels au cours d'interventions chirurgicales pelviennes, notamment la prostatectomie et la cystoprostatectomie radicales, puisse être responsable d'impuissance d'origine vasculaire. La reconnaissance des ces artères avant l'intervention par écho-Doppler couleur devrait permettre d'envisager leur préservation.

L'absence de shunts artério-veineux cavernospongieux et de drainage veineux spongieux à travers les corps caverneux plaide en faveur d'un passage artériel spongio-caverneux des substances pharmacologiques. L'existence de ces anastomoses artérielles permet d'envisager de nouvelles possibilités de revascularisation chirurgicale des corps caverneux mais également les risques de la chirurgie de l'urètre pénien et du corps spongieux. 
NOTRE EXPERIENCE DES AUTO-INJECTIONS INTRACAVERNEUSES DANS LES DYSFONCTIONS ERECTILES (DE) : MOXISYLYTE, PROSTAGLANDINE E1 (PGE1) ET ASSOCIATION PAPAVERINE-PHENTOLAMINE-PGE1

\author{
A Lemaire, J.Buvat \\ Association EPARP 47-49 rue de la Bassée, \\ 59000 Lille, France
}

Nous avons comparé dans cette étude rétrospective l'efficacité et les effets secondaires des 3 principales substances que nous avons utilisées pour les auto-injections intracaverneuses (autoIIC) jusque Juin 1996 : la prostaglandine E1 (P), le moxisylyte $(\mathrm{M})$, et l'association papavérine phentolamine prostaglandine E1 (PPP) que nous avons réservée aux échecs de la seule $P$.

\section{Patients et méthodes}

Cette étude concerne 351 patients ayant consulté notre centre pour DE depuis 1985, et ayant souhaité essayer les auto-injections intracave- meuses (auto-IIC). 159 ont été inclus dans le programme MOXISYLYTE (ICAVEX®), ERECNOSß à partir de Juin 1985. A partir d'Octobre 1989, 209 ont re,cu de la PGE1 (CAVERJECT®), EDEX(). Enfin, à partir de Juin 1992, 28 patients résistant à la seule $\mathrm{P}$ ont été traités par un mélange contenant par $\mathrm{ml} 8 \mathrm{mg}$ de papavérine, $0.2 \mathrm{mg}$ de phentolamine et $10 \mu \mathrm{g}$ de PGE1. Dans la plupart des cas, l'étiologie de la DE avait été déterminée avant traitement par les antécédents du patient, l'examen clinique, l'évaluation psychologique hormonale, le pharmacodoppler pulsé, les explorations neurophysiologiques, la rigidimétrie nocturne et parfois la cavernométrie avec cavernographie. Les patients étaient ainsi répartis en psychologiques, artériels, neurologiques.

\section{Résultats et commentaires}

L'âge moyen des patients était de $49.5 \pm 10$ ans, sans différence significative entre les 3 groupes. Les 159 patients du groupe $M$ furent suivis pendant 20-48 mois (durée moyenne par patient : $13.6 \pm 17.3$ mois). Ils effectuèrent 8979 injections

Tableau 1: Efficacité dans l'ensemble des cas

\begin{tabular}{lllll}
\hline & bon & moyen & médiocre & épuisement secondaire \\
groupe M & $85(53.4 \%)$ & $27(16.9 \%)$ & $31(19.5 \%)$ & $5(0.3 \%)$ \\
groupe P & $145(69.7 \%)$ & $31(14.9 \%)$ & $23(11.1 \%)$ & $4(1.9 \%)$ \\
groupe PPP & $20(71.4 \%)$ & $3(10.7 \%)$ & $4(14.2 \%)$ & $1(0.3 \%)$ \\
\hline
\end{tabular}

Tableau 2 : Proportion des sujets avec efficacité bonne ou movenne selon l'étiologie.

\begin{tabular}{lllll}
\hline ETIOLOGE $=\Rightarrow$ & psychologique & neurologique & artérielle & dysf. veinoocclusive \\
groupe M & $62 / 82(75.6 \%)$ & $10 / 14(71.4 \%)$ & $20 / 28(71.4 \%)$ & $0 / 8(0 \%)$ \\
groupe P & $73 / 81(90.1 \%)$ & $19 / 19(100 \%)$ & $34 / 36(94.4 \%)$ & $8 / 18(44.4 \%)$ \\
groupe.PPP & $11 / 12$ & $3 / 4$ & 213 & $1 / 1$ \\
\hline
\end{tabular}

Tableau 3 : Effets indésirables.

\begin{tabular}{llll}
\hline & groupe $\mathbf{M}$ & groupe P & groupe PPP \\
erection > 2 heures & $1(0.6 \%)$ & $15(7.1 \%)$ & $3(10 \%)$ \\
érection > 4 heures & $1(0.6 \%)$ & $4(1.9 \%)$ & $\mathbf{1}(3.5 \%)$ \\
érection > 6 heures & & $2(0.9 \%)$ & \\
$\quad$ dont traitée : & $2(1.2 \%)$ & $1(0.4 \%)$ & $\mathbf{1}(3.5 \%)$ \\
douleur locale & & $14(6.6 \%)$ & $25(89.2 \%)$ \\
douleur diffuse & $2(1.2 \%)$ & $6(2.8 \%)$ & $\mathbf{1}(3.5 \%)$ \\
fibrose & $6(3.8 \%)$ & $\mathbf{9}(\mathbf{4 . 3 \%})$ & $2(7.1 \%)$ \\
éjaculation relardée & $6(3.8 \%)$ & $1(0.4 \%)$ & \\
malaises après injection & & & \\
\hline
\end{tabular}


(soit 56.4/patient et $4.4 /$ mois). Les 209 patients du groupe $P$ furent suivis pendant 3440 mois (durée moyenne par patient : $16.5 \pm 15.4$ mois). Ils effectuèrent 16447 injections (soit 79/patient et $4,7 /$ mois). Les 28 patients du groupe PPP furent suivis pendant 237 mois (durée moyenne par patient : $8.5 \pm 7.9$ mois). 959 injections furent effectuées (soit 34/patient et $4 /$ mois). L'efficacité fut jugée bonne quand plus de $75 \%$ des injections permettaient un rapport satisfaisant et moyenne quand le taux de succés des rapports était inférieur à $75 \%$ ou que la rigidité n'était pas totalement satisfaisante (Tableau 1).

La PGE1 semble donc plus effcace que le $\mathrm{M}$, et ceci apparait encore mieux sur le tableau 2 qui montre l'efficacité selon l'étiologie. Cependant les différences ne sont pas significatives, probablement du fait d'une sélection progressive des indications de chaque substance avec l'expérience.

Les effets indésirables sont listés dans le tableau 3.

\section{Conclusion}

Les résultats de cette étude suggèrent une plus grande efficacité de la PGE1. Bien que moins puissant, le moxisylyte a l'avantage d'induire moins d'érections prolongées et de douleurs. I1 peut donc trouver son intérêt en première intention pour les praticiens peu expérimentés et chez les sujets trés sensibles aux injections et donc à risque de priapisme ainsi qu'en cas de douleur récurrente après PGE1. L'association PPP, quant à elle, est bien tolérée au moins lorsqu'elle est réservée aux echecs de la seule PGE1, et élargit manifestement les possibilités du traitement par auto-IIC.

$\bullet$

\section{LE SILDENAFIL (VIAGRA,), UN NOUVEAU TRAITEMENT ORAL DES DYSFONCTIONS ERECTILES : ETUDE MULTICENTRIQUE EN DOUBLE INSU CONTRE PLACEBO CHEZ 351 PATIENTS}

\author{
J. Buvat*, C. GINGELL**, A. OlSSON***, A. JAR- \\ Dina, A. Lemaire*, F.Giuliano ${ }^{\circ}$, I. OSTERLOH ${ }^{\circ}$, \\ J. KIRKPATRICK ${ }^{\circ}$, M. CUDDIGANS, ET LE GROUPE \\ MULTICENTRIQUE
}

\footnotetext{
*Association EPARP, 49 rue de la Bassée, 59000 Lille **Southmead Hospital, Bristol, Grande Bretagne ***Lund, Suéde ; Kremlin-Bicêtre, Paris, France. ${ }^{\circ}$ Pfizer Research Center, Sandwich, Grande Bretagne.
}

\section{Buts}

Il est maintenant admis que la relaxation du muscle lisse caverneux qui génère l'érection est la conséquence d'une libération d'oxyde nitrique sous l'effet de la stimulation sexuelle. Il en résulte une augmentation de la production de guanosine monophosphate cyclique (GMPC) qui, à son tour, diminue le calcium intracellulaire. Le Sildenafil est un inhibiteur selectif puissant de la phosphodiesterase de type 5, principal enzyme hydrolysant la GMPC dans les corps caverneux. De ce fait il devrait renforcer la relaxation du muscle lisse caverneux résultant de la libération d'oxyde nitrique, et donc la réponse érectile à la stimulation sexuelle. Cette étude multicentrique européenne a testé l'intérêt thérapeutique de son administration quotidienne à différentes doses dans des dysfonctions érectiles (DE).

\section{Matériel et méthodes}

Cet essai (Protocole 148-353) a inclus 351 hommes (24 à 70 ans, âge moyen 53) avec DE sans cause organique connue (durée moyenne 4.5 ans). Après une période d'observation de 2 semaines, ils ont reçu chaque jour pendant 28 jours $10 \mathrm{mg}(\mathrm{n}=90), 25 \mathrm{mg}(\mathrm{n}=85)$ ou $50 \mathrm{mg}(\mathrm{n}$ $=81$ ) de Sildenafil, ou un placebo $(n=95)$, l'attribution ayant été randomisée en double insu. Les sujets ont encore été suivis deux semaines après l'arrêt du traitement.

L'évaluation des effets sur la fonction sexuelle a fait appel à un relevé quotidien des érections, un autoquestionnaire en $\mathbf{1 5}$ points rempli toutes les 2 semaines, à l'opinion du patient sur une éventuelle amélioration des ses érections et, de façon facultative, à un questionnaire rempli par la partenaire au début et à la fin du traitement. La tolérance clinique et biologique a été évaluée à intervalles réguliers.

\section{Résultats}

Les proportions des patients ayant répondu que le traitement avait amélioré leurs érections furent de $38 \%$ avec le placebo, $65 \%$ avec $10 \mathrm{mg}$, $79 \%$ avec $25 \mathrm{mg}$ et $89 \%$ avec $50 \mathrm{mg}(\mathrm{P}<0.0001$ en faveur du traitement). Les proportions de ceux souhaitant poursuivre le traitement après la fin de l'étude furent de $51 \%$ (Placebo), $79 \%$ $(10 \mathrm{mg}), 85 \%(25 \mathrm{mg})$ et $91 \%(50 \mathrm{mg})(\mathrm{P}<$ $0.0001)$. L'analyse des autoquestionnaires objectiva les mêmes relations dose-réponse en ce qui concerne la fréquence, la rigidité et la durée des 
érections $(\mathrm{P}<0.005$ à 0.0001$)$, et les autres paramètres de la vie sexuelle y compris le nombre de rapports satisfaisants et la qualité de la vie sexuelle $(P<0.001)$, mais il n'y eût pas d'effet discernable sur la libido (Pas d'augmentation du nombre d'essais sexuels). Les questionnaires remplis par les partenaires confirmèrent l'effet dose-réponse significatif sur la qualité des érections et sur la vie sexuelle $(\mathrm{P}<0.005)$. La tolérance fut dans l'ensemble bonne, les principaux effets indésirables potentiellement liés au traitement étant des céphalées ( 13 à $20 \%$ selon la dose), une vaso-dilatation ou un flush (4 à $9 \%$ ), une dyspepsie ( 4 à $11 \%$ ) et des myalgies ( 1 à $7 \%$ ), le plus souvent minimes ou modérés. Les arrêts de traitement pour effet indésirable ne furent pas plus fréquents sous Sildenafil que sous placebo $(<5 \%)$.

\section{Conclusions}

Ces résultats démontrent que l'administration orale de Sildenafil est un traitement efficace et bien toléré des dysfonctions érectiles sans cause organique connue. Ils confirment l'importance du système oxyde nitrique-GMPC dans l'érection humaine, et soulignent l'importance du rôle de la phosphodiesterase du type 5 .

\section{$-\bullet$}

\section{ALPROSTADIL-ALPHADEX VERSUS MOXISYLYTE DANS LE TRAITEMENT DES DYSFONCTIONS ERECTILES PAR INJECTION INTRACAVERNEUSES : RESULTATS D'UNE ETUDE MULTICEN- TRIQUE EN DOUBLE INSU}

J. Buvat **, D. MorlaER ${ }^{* *}$, P. COSTA***, D. CHEVALLIER ${ }^{\circ}$, M. ZerLiB ${ }^{\circ}$, A. Lemaire* ET Le GRoupe D'ETUde

* Association EPARP, Lille;

** Hôpital Tenon, Paris ;

***Hôpital G. Doumergue, Nîmes ;

${ }^{\circ}$ Hôpital Pasteur, 30 voie romaine, 06000 Nice ;

${ }^{\circ}$ Hôpital Cochin, 27 rue du Faubourg St Jacques, 75014 Paris.

\section{Buts}

Comparer objectivement l'efficacité et la tolérance des deux seuls composés ayant obtenu l'autorisation de mise sur le marché dans l'indication des injections intracaverneuses, l'Alprostadil et le Moxisylyte.

\section{Matériel et méthodes}

Etude prospective avec groupes parallèles et doses croissantes menée dans 13 centres français. 156 sujets (53.7 +/- 10-8 ans) avec dysfonction érectile chronique (durée moyenne 4 ans et 5 mois) ont été inclus et ont reçu chacun 3 injections d'Alprostadil Alphadex (AA, Edex, 5 à 20 $\mathrm{mg}$ ) ou de Moxisylyte, Icavex ${ }^{\circledR}, 5$ à $20 \mathrm{mg}$ ) simultanément à l'apprentissage des auto-injections. L'étude a pu être menée en double-insu grâce à une préparation des injections dans des seringues identiques par une tierce personne indépendante (pharmacien ou médecin). Au cours de cette première phase, le principal critère d'efficacité fut l'objectivation d'une rigidité axiale par le buckling test ( $>1 \mathrm{~kg}$ pendant au moins $60 \mathrm{mn}$ ). Les sujets qui présentèrent une érection adéquate au cours de cette phase participèrent à une seconde phase au cours de laquelle ils purent faire jusqu'à 6 auto-injections de la dose optimale déterminée précédemment. Les résultats de cette seconde phase furent évaluées par auto-questionnaires, échelles analogiques visuelles (satisfaction du sujet et de sa partenaire) et entretiens.

\section{Résultats}

Pendant la phase d'apprentissage, $75 \%$ des sujets du groupe Alprostadil-Alphadex présentèrent au moins un buckling test positif contre seulement $40 \%$ de ceux du groupe Moxisylyte ( $p$ $<0.001$ ). Le taux des sujets ayant présenté au moins une érection compatible avec un rapport selon l'investigateur fut équivalent ( $81 \%$ vs 48 $\%, \mathrm{p}<0.001) .8$ sujets Mox $(9 \%)$ contre un seul sujet AA (1\%) interrompirent l'étude pour manque d'efficacité. Des érections prolongées (> 2h) survinrent chez 4 sujets du groupe AA (5\%) contre aucun du groupe Mox. Les incidences des saignements et des douleurs pendant l'érection ne différèrent pas. Par contre les douleurs pendant et après l'érection furent plus fréquentes après $\mathrm{AA}(17 \%)$ qu'après Mox $(5 \%)(\mathrm{p}<0.001)$. $\mathrm{Au}$ cours de la phase des auto-injections, le pourcentage des sujets ayant obtenu au moins 1 fois une érection rigide fut plus élevé dans le groupe AA ( $85 \%$ vs $61 \%$ dans le groupe Mox, p $<0.001$ ).

Le pourcentage des auto-injections efficaces fut également plus élevé dans le groupe AA (61\% vs $44 \%, \mathrm{p}<0.05$ ). Les sujets du groupe Mox rapportèrent plus de sensations ébrieuses et lipo- 
thymiques( $8 \%$ vs $1 \% \mathrm{~ns}$ ), et ceux du groupe AA plus de douleurs pendant (24\% vs $3 \%, \mathrm{p}<$ $0.001)$ ou après ( $19 \%$ vs $5 \%, \mathrm{p}<0.05)$ l'érection, et plus d'érections prolongées ( $4 \%$ vs $2 \%, \mathrm{NS}$ ) mais les échelles analogiques visuelles montrèrent un degré de satisfaction significativement supérieur avec l'AA tant chez les sujets ( $p<$ $0.001)$ que chez leurs partenaires $(\mathrm{p}<0.01)$.

\section{Commentaires et conclusions}

L'Alprostadil Alphadex est significativement plus efficace que le Moxisylyte tant au cabinet qu'à domicile. Les effets indésirables liés au processus d'injection surviennent à la même fréquence avec les deux substances. Le Mox induit plus d'effets systémiques et la PGE1 plus d'érections prolongées et douloureuses. Cependant les deux partenaires sont significativement plus satisfaits de l'utilisation de l'Alprostadil Alphadex.

\section{IMAGERIE MEDICALE}

ECHO-DOPPLER DES VEINES SPERMATIQUES AVANT ET APRES EMBOLISATION: UNE MEILLEURE CLASSIFICATION DES VARICOCELES INFRA-CLINIQUES ?

\author{
F. Cornud ${ }^{*}$ D. Delafontaine**, E. Amar ${ }^{\circ}$, F. \\ OLIVENNES ${ }^{\circ}$, R. FANCHIN ${ }^{\circ \circ}$ \\ *Clinique Radiologique, **Médecine de la repro- \\ duction, ${ }^{\circ}$ Uro-Andrologue, ${ }^{\circ} \mathrm{Hopital}$ Antoine- \\ Béclère,Paris, France
}

\section{Introduction-Buts}

Montrer l'évolution des reflux veineux spermatiques mesurés par écho-Doppler pulsé chez 199 patients traités par embolisation des veines spermatiques.

\section{Matériel et Méthodes}

231 veines refluantes ont été enregistrées chez 199 patients examinés pour varicocèle palpable avec scrotalgies (29 cas) et/ou oligozoospermie (202 cas). Dans 207 cas (168 à gauche et 39 à droite), le reflux était durable ( $>2$ secondes) et en plateau pendant toute la durée de la manœuvre de Valsalva. Dans 24 cas, sans vari- cocèle palpable, le reflux durait moins de 2 secondes et avait un aspect décroissant.

\section{Résultats}

Parmi les 207 reflux durables, 147 (71\%) étaient palpables (140 fois à gauche et 7 fois des deux côtés). Après embolisation, le Doppler montrait l' absence de reflux dans 152 cas (73\%), la persistance d'un reflux non durable dans 36 cas (17\%) (avec disparition clinique du varicocèle) et un reflux inchangé dans 19 cas (10\%) (avec persistance clinique du varicocèle). Parmi les 24 reflux non durables, $12(50 \%)$ avaient disparu (malgré un échec de phlébographie),et $12(50 \%)$ persistaient avec un aspect Doppler identique.

Parmi ceux-ci, 3 n'avaient pas été embolisés (veine spermatique droite continente) et 1 échec de phlébographie avait été observé.

\section{Discussion}

En l'absence de varicocèle palpable, l' écho-Doppler détecte dans $30 \%$ des cas un reflux durable assimilable à un varicocèle infraclinique. Il isole également les reflux non durables qui ne correspondent vraisemblablement pas à une incontinence veineuse pathologique.

\section{ECHOGRAPHIE ET IRM ENDORECTALES DE L'OBSTRUCTION DES CANAUX EJA- CULATEURS CHEZ LHOMME HYPOFERTILE}

\author{
F. Cornud ${ }^{* 0}$, E. Amar**, D. Delafontaine ${ }^{\circ}, \mathrm{X}$ \\ Belin $^{*}, \circ$, J. Mandelbaum ${ }^{\circ}$, O. Helenon ${ }^{\circ \circ}$, J.F \\ MOREAU $^{\circ \circ}$ \\ *Clinique radiologique, ${ }^{* *}$ Uro-Andrologue, \\ ${ }^{\circ}$ Médecine de la reproduction, ${ }^{\circ}$ Hopital Necker, \\ Paris, France
}

\section{Introduction}

Décrire les aspects échographiques et par IRM endorectale de l'obstruction des canaux éjaculateurs chez 33 patients hypofertiles.

\section{Matériel et Méthode}

31 patients avaient un volume de l'éjaculat $<1,5$ $\mathrm{ml}$. Le fructose était bas ou effondré chez 30 patients. Le spermogramme montrait une azoospermie ou une oligozoospermie sévère dans 29 cas et une oligozoospermie modérée dans 4 cas. L' IBM endorectale a été réalisée dans 14 cas. 
Les malades avec une absence des deux canaux déférents ont eu une échographie rénale et une recherche des mutations de la mucoviscidose. Une vésiculographie par voie transrectale a été réalisée dans 3 cas.

\section{Résultats}

Vingt patients étaient atteints d'une absence bilatérale et congénitale des canaux déférents; l'échographie montrait une absence bilatérale des deux ampoules déférentielles chez 18 d'entre eux avec conservation d'une ou des deux vésicules séminales et d'un ou des deux canaux éjaculateurs dans 9 cas. L' IRM montrait un hyposignal diffus de la zone périphérique. Dans 12 cas, l'obstacle était dû a une sténose inflamatoire des canaux éjaculateurs et dans un cas a un kyste médian.

\section{Discussion}

L'imagerie du carrefour urogénital permet le diagnostic d'obstacle distal des canaux éjaculateurs en s'aidant dans les cas douteux d'une vésiculographie percutanée. L'IBM donne des renseignements anatomiques précieux quand une résection endoscopique des canaux est envisagée.

\section{HORMONES, ANTI-HORMONES, SEXUALITE}

\section{EFFETS METABOLIQUES D'UN TRAITE- MENT PAR OESTROGENES NATURELS ET ANTIANDROGENES CHEZ LES HOMMES TRANSSEXUELS}

\section{Kh. ARAFAT*, M. HANSS**, P. MOULIN*, G. TRONCY**, M. Dechavanne*, F. Berthezene*, J. Rollet* \\ * Service d'Endocrinologie et des Maladies de la Nutrition. Hôpital de l'Antiquaille. ${ }^{* *}$ Laboratoi- re d'Hémostase Hôpital Neuro Cardio Lyon}

L'administration de fortes doses d'oestrogènes synthétiques par voie orale chez l'homme s'accompagne d'une hypertriglycéridémie et d'une augmentation du risque thrombo-embolique. Inversement les œstrogènes naturels administrés à dose substitutive chez la femme semblent avoir un effet prothrombogène moindre et pourraient exercer un effet bénéfique sur le risque vasculaire. Nous avons voulu apprécier, chez des hommes transsexuels, le risque potentiel lié à l'utilisation prolongée d'oestrogènes naturels associés aux antiandrogènes. Les effets d'un traitement par $17 \beta$ œstradiol per os $(2 \mathrm{mg} / \mathrm{j})$ associé à de l'acétate de cyprotérone $(50 \mathrm{mg} / \mathrm{j})$ ont été étudiés chez 6 hommes durant 5 mois après une période d'observation de 4 semaines. Aucune variation significative de la cholestérolémie totale, des concentrations du cholestérol LDL, de l'apo B ou du cholestérol HDL n'a été observée. En revanche la triglycéridémie a diminuée de $37+8 \%$ (MO vs M5 p <0.05). Cette variation s'est accompagnée d'une diminution parallèle du facteur VII ag de $14 \pm 0.4 \%$ (MO vs M5 $\mathrm{p}<0.05$ ). Les autres paramètres de la coagulation ou de la thrombose : Protéine C, Protéine $\mathrm{S}$, Anti Thrombine Ill, PAI 1 , fibrinogène n'ont pas variés de façon significative. Les concentrations et les variations sous traitement des triglycérides et du facteur VII, protéines synthétisées par l'hépatocyte se sont avérées étroitement corrélées $(r=0.656 n=18 p<0.005$ et $r=0.81 n=6$ $p=0.05$ ). Ces données suggèrent que chez l'homme, de faibles doses d'oestrogènes naturels administrés par voie orale, associés à un traitement anti androgènique n'ont pas d'effets métaboliques néfastes détectables sur les lipoprotéines et les paramètres de l'hémostase.

Leurs effets à long terme sur le risque vasculaire restent à établir.

\section{ETUDE DE LA FONCTION SEXUELLE DES HOMMES TRANSPLANTES RENAUX}

B. BARrou, F. Kirsch-NoIR, J. Hubert, G. Fournier, J. Petit, T. Lebret, B. Cuzin, G. Karam, F. Giuliano, et les Membres des Comites DE TRANSPLANTATION ET D'ANDROLOGIE DE L'ASSOCIATION FrançaISE D'URoLogIE

\section{Introduction}

Il n'existe que peu d'études sur la sexualité masculine après transplantation rénale; elles sont souvent anciennes, rétrospectives et ne concernent que peu de patients.

\section{But de l'étude}

Evaluer la fréquence de ces troubles, leur nature et leur retentissement, et déterminer l'effet de la 
greffe rénale sur ceux-ci, au moyen d'une étude multicentrique rétrospective.

\section{Patients et méthodes}

Cette étude coordonnée par les Comités de Transplantation et d'Andrologie de l'AFU a étudié dans 8 centres français les hommes transplantés du 01/01/1994 au 31/12/95. Un questionnaire médical a été rempli pour chaque patient par les investigateurs. Deux autoquestionnaires ont été adressés aux patients, l'un portant sur la description des troubles avant puis après transplantation, l'autre, questionnaire psychotechnique SCL $90-R$, visant à déterminer leur état psychologique et émotionnel. Les résultats ont été l'objet d'une double saisie et d'une analyse statistique par une société spécialisée.

\section{Résultats}

282 patients ont été inclus. $170(60,2 \%)$ ont accepté de remplir les autoquestionnaires. Les troubles prédominants concernent le désir sexuel $(69 \%)$ avec une sexualité globalement insatisfaisante (63\%). La dysfonction érectile est moins fréquente : $68 \%$ ont des érections spontanées mais $45 \%$ signalent une tumescence et une rigidité imparfaites. $33,3 \%$ ont vu leurs troubles améliorés par la greffe, $27,9 \%$ ont été aggravés alors que $38,8 \%$ ne signalent pas de modification. Les facteurs qui influencent significativement l'évolution des troubles après greffe ont été l'âge, l'origine du greffon, la reprise d'une activité professionnelle après greffe et le profil psychologique. Seuls $21,8 \%$ des patients parlent spontanément de leurs troubles et $7 \%$ sont pris en charge. Toutefois, une majorité $(60 \%)$ est prête à suivre un traitement.

\section{Conclusion}

L'amélioration de la prise en charge des troubles sexuels des patients greffés semble non seulement possible mais aussi souhaitable.

TAMOXIFENE PAR VOIE ORALE : UNE ALTERNATIVE THERAPEUTIQUE NON CHIRURGICALE DANS LE TRAITEMENT DE LA MALADIE DE LA PEYRONIE?

L. Sibert, E. Barret, C. Pfister, M. Planet, P. Grise Charles-Nicolle, 76031 Rouen cedex

\section{Introduction}

Le but de cette étude a été d'évaluer l'efficacité clinique du Tamoxifène administré par voie orale dans le traitement de la maladie de La Peyronie.

\section{Matériel et Méthodes}

Une étude prospective a été réalisée sur des patients porteurs d'une maladie de La Peyronie et recevant $20 \mathrm{mg}$ de Tamoxifene par jour per os. Une évaluation clinique a été effectuée tous les 3 mois. A chaque consultation, le niveau de la douleur, la taille de la plaque et le dégré d'angulation après érection pharmacologiquement induite ont été relevés.

\section{Résultats}

De janvier 1994 à avril 1996, 20 patients (âge moyen 55 ans, extrêmes 40-71 ans) ont reçu du Tamoxifène, le recul moyen était de 11 mois (extrêmes 4-28 mois). Le délai moyen entre le début des symptômes et le début du traitement était de 10 mois (extrêmes 3 mois-3 ans). La douleur a été améliorée chez 12 patients $(60 \%)$, la taille de la plaque a significativement diminué (d'au moins $1 \mathrm{~cm}$ ) chez 7 patients $(35 \%)$, l'angulation a diminué (d'au moins $10^{\circ}$ ) chez 5 patients $(25 \%) .2$ patients ont été opérés après 4 et 8 mois de traitement. Le taux global de réponse a été de $41 \%$.

\section{Conclusion}

In vitro le tamoxifène diminue la fibrose par une action anti-inflammatoire, grâce à la désactivation des lymphocytes $T$ et l'augmentation de production du T.G.F.b. La principale réponse clinique porte surtout sur l'amélioration de la douleur. L'efficacité sur la taille de la plaque et l'angulation est faible. Les meilleurs résultats $\mathrm{du}$ Tamoxifène comme des autres traitements médicaux semblent devoir survenir sur des maladies de La Peyronie diagnostiquées tôt (4 mois), avec une plaque inférieure à $2 \mathrm{~cm}$ et une angulation inférieure à $30^{\circ}$.

Sous réserve d'études prospectives comparatives plus large, la chirurgie est encore le traitement de référence pour les maladies de La Peyronie évoluées. 